\title{
A MULTIPLE REGRESSION ANALYSIS OF CARDIOVASCULAR HEALTH RISKS OF EXPOSURE TO ENVIRONMENTAL STRESSORS IN TORONTO, CANADA
}

$$
\text { by }
$$

\author{
DANIELLE SADAKHOM \\ Honours Bachelor of Environmental Studies, York University, \\ 2016
}

A thesis presented to Ryerson University

in partial fulfillment of the requirements for the degree of

Master of Applied Science

in the program of

Environmental Applied Science and Management

Toronto, Ontario, Canada, 2018

(C) Danielle Sadakhom, 2018 


\begin{abstract}
Author's Declaration
This thesis is a manuscript style thesis made up of one paper prepared for publication in the journal Social Science and Medicine. Although the manuscript is co-authored with my thesis supervisor, Dr. Tor Oiamo (Ryerson University) and Dr. Jeff Brook (Environment Canada), I have conducted the majority of the research, which included literature review, data linkage of environmental exposure data and the Canadian Community Health Survey dataset in the Statistics Canada Research Data Centre, data analysis, and writing. Dr. Oiamo provided input on the structure of the manuscript and created the noise exposure dataset, and Dr. Brook facilitated access to air quality data through the Canadian Urban Environmental Health Research Consortium (CANUE).
\end{abstract}

This is a true copy of the thesis, including any required final revisions, as accepted by my examiners.

I authorize Ryerson University to lend this thesis to other institutions or individuals for the purpose of scholarly research.

I further authorize Ryerson University to reproduce this thesis by photocopying or by other means, in total or in part, at the request of other institutions for the purpose of scholarly research.

I understand that my thesis may be made electronically available to the public. 


\title{
A MULTIPLE REGRESSION ANALYSIS OF CARDIOVASCULAR HEALTH RISKS OF EXPOSURE TO ENVIRONMENTAL STRESSORS IN TORONTO, CANADA
}

Master of Applied Science, 2018

Danielle Sadakhom

Environmental Applied Science and Management

Ryerson University

\begin{abstract}
This thesis examines the effects of exposure to ambient noise and air pollution and access to available greenspace on cardiovascular health in Toronto, Ontario. The study is focused around the population health approach which is used to understand the health of the whole population and to reduce health inequalities amongst population groups. The study utilizes population data from the 2012-2014 Canadian Community Health Survey (CCHS), air quality data from 20102014, noise exposure data from 2016, and the DMTI land use parks and recreation data to conduct a logistic regression analysis. The results from the analysis showed significant effects for noise when evaluated individually and measured cumulatively with air pollution and greenspace. Greenspace showed significant results when controlling for behavioural covariates, whereas air pollution displayed conflicting results for acute exposure. Future research on multiple environmental stressors should look to validate the importance of both ambient stressors through a longitudinal study.
\end{abstract}




\section{Acknowledgements}

I would first like to thank my thesis supervisor Dr. Tor Oiamo of the Department of Geography and Environmental Studies at Ryerson University. Thank you for never giving up on me and for the patient guidance, encouragement and advice you have provided throughout my time as your student. I am beyond grateful to have had a supervisor who cared so much about my success.

I would also like to thank my friends at Ryerson for their overwhelming support who have made my experience unforgettable. Thank you, Toki, Victoria, Desi, Fatima, Rachel, and Ali, for all the laughs and wonderful memories.

Finally, I would like to thank my mom Carolyn, my father Manoune, and my brother Alexander, for the unconditional love and support you have always given me. Thank you to the rest of my family- Sophie, aunt Joan, aunt Linda, aunt Marilyn, aunt Lisa, uncle Reggie, Eric, and Andrea. To my old friends who have never stopped believing in me- Mae, JP, Adrian, Paige, Ron, Nick, Franco, Jake, and Elaine.

To my late grandfather John Gilbert, this is for you. I hope I've made you proud. 


\section{Table of Contents}

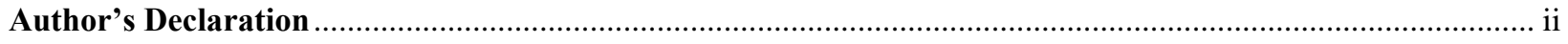

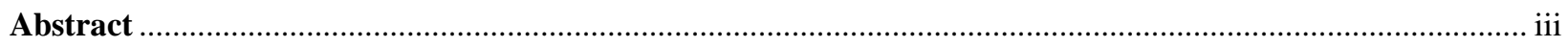

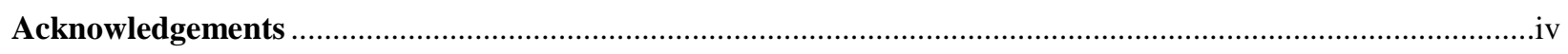

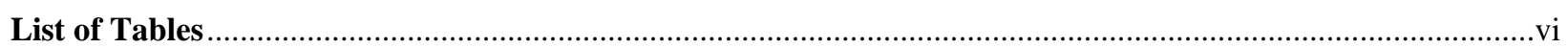

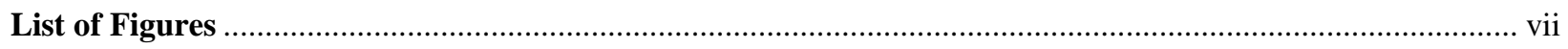

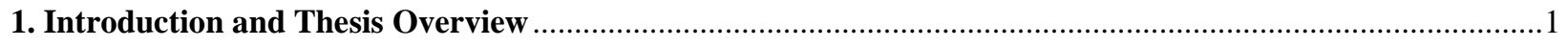

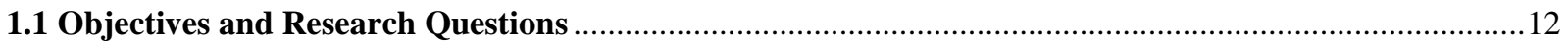

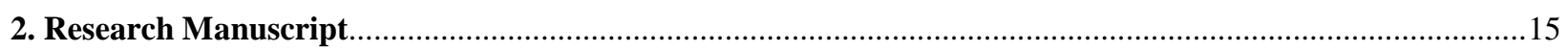

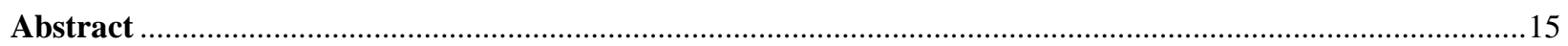

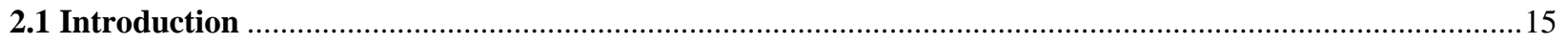

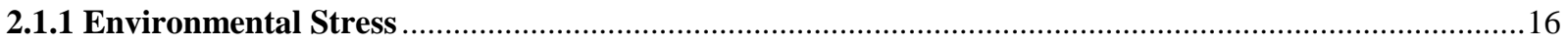

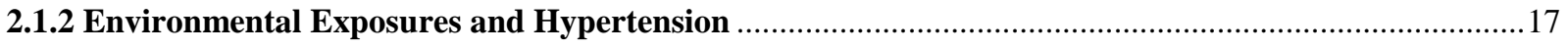

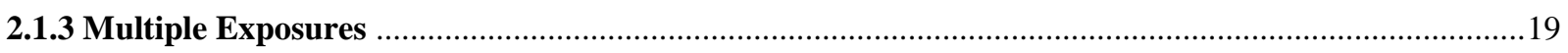

2.1.4 Greenspace

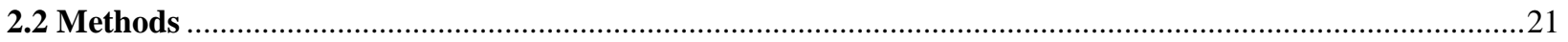

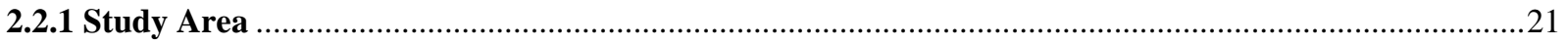

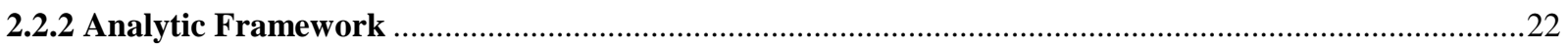

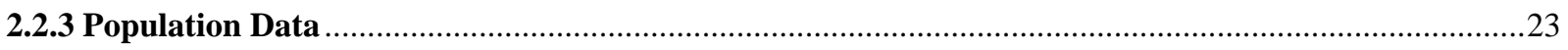

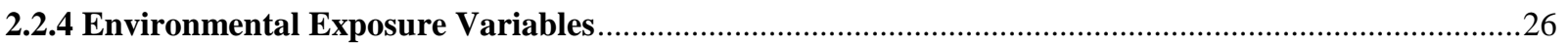

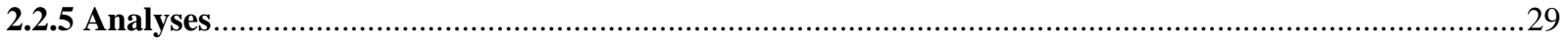

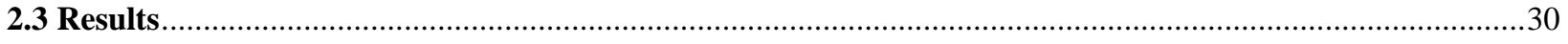

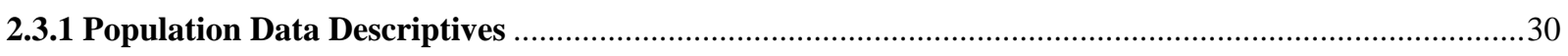

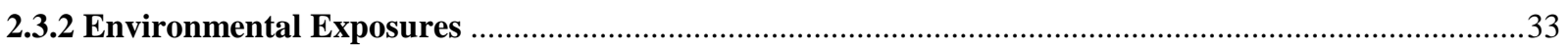

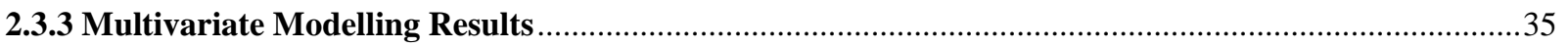

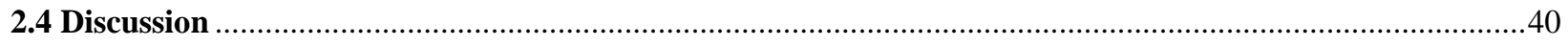

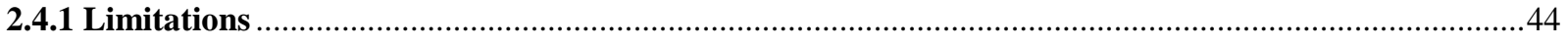

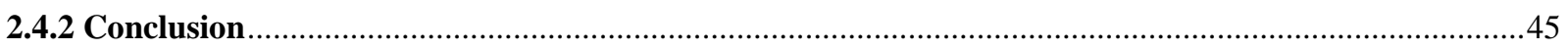

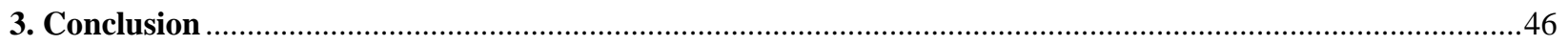

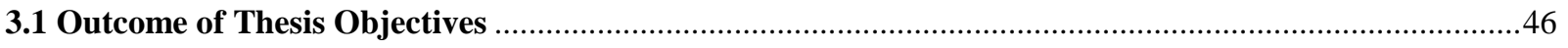

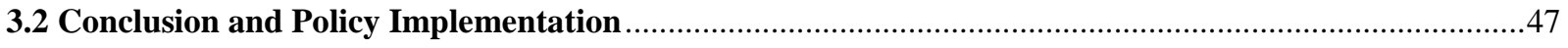

Appendices …

APPENDIX A: Project proposal application to access the Research Data Centre (RDC) ...........................51

APPENDIX B: Canadian Community Health Survey (CCHS) - 2012 Data Dictionary ...............................56

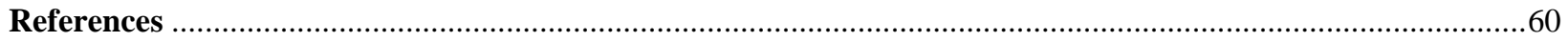




\section{List of Tables}

Table 1 Descriptive table of the variables used from the CCHS 2012 \& 2013/2014 dataset 31 Table 2 ANOVA comparing categorical variables with NO2 …................................ 31

Table 3 Chi-square matrix between categorical variables .......................................... 33

Table 4 Descriptive statistics for environmental exposures …..................................... 33

Table 5 Logistic regression of noise effects on hypertension ......................................... 35

Table 6 Logistic regression of greenspace effects on hypertension ................................. 36

Table 7 Logistic regression results of the noise effects on hypertension when controlling for

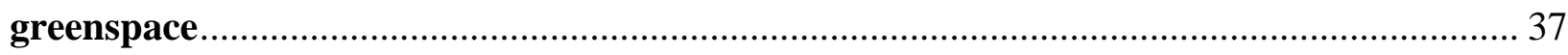

Table 8 Logistic regression results of the air quality effects on hypertension ................... 38

Table 9 Logistic regression results of the effects of multiple environmental exposures on

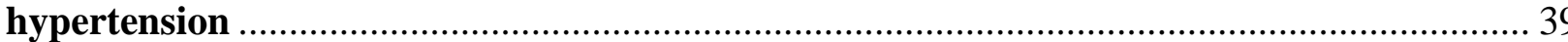




\section{List of Figures}

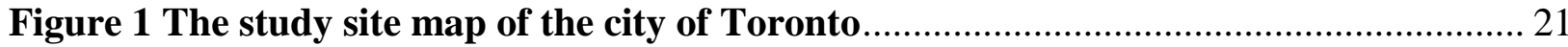

Figure 2 Framework of proposed health effects of environmental stressors .................... 22

Figure 3 The greenspace map of parks and recreation areas in the city of Toronto.......... 28

Figure 4 Map of 24-hour traffic noise distribution in the city of Toronto......................... 34

Figure 5 Map of Nitrogen Dioxide (NO2) distribution in the city of Toronto ..................... 35 


\section{Introduction and Thesis Overview}

In the Canadian context, the health field has primarily focused on assessing health concerns through traditional medical ideologies by evaluating an individual patient's state. (Lalonde, 1974). Primary health care in Canada was traditionally determined by the absence or presence of a disease, measured by the quality of medicine (Lalonde, 1974). The World Health Organization (1948) defined health as "a state of complete physical, mental and social well-being and not merely the absence of disease or infirmity". However, given the transition of the health field over the past century, the World Health Organization's definition of health is viewed as no longer applicable in current times (Leonardi, 2018). There are barriers to change the universally known definition of health since health itself is complex. First, there is an unwillingness by the World Health Organization to change their definition of health, and second, there is no substitute perspective that has been universally accepted by all (Leonardi, 2018). Although progress has been made in the public health sector directed towards improving the health of Canadians, accessible healthcare amongst all provinces and territories lacks equity (Lalonde, 1974; Moloughney, 2004). The most recent views have focused more on health as a unique perspective based on one's experience rather than a universal definition as every interaction individuals make is different (Leonardi, 2018). The newer view to health can be attributed to the success of Lalonde's white paper.

Marc Lalonde's white paper a new perspective on the health of Canadians was one of the first Canadian public health documents acknowledging that the traditional view of health is inadequate (Epp, J., 1986). From this document, Lalonde introduced the "Health Field Concept" aligning with the World Health Organization's definition of health. The report urged public health officials to confront medical challenges using the four health fields he believed were the 
underlying causes of illness and death in Canada (Lalonde, 1974). The Health Field Concept is separated into four interdependent categories of study: human biology, lifestyle, health care organization, and environment (Lalonde, 1974).

According to Lalonde, the human biology category includes every feature associated with both the mental and physical state of the human body, which consists of the genetic inheritance, the aging process, and the internal systems (Lalonde, 1974). The lifestyle category pertains to the personal habits and decisions that can affect the quality of health of an individual, including choices made regarding dietary and fitness habits (Lalonde, 1974). The lifestyle category also recognises that bad health choices made by an individual can generate self-imposed risks (Lalonde, 1974). The environment, defined by Lalonde is everything outside the human body that an individual does not have full control over (1974). Environmental factors include environmental hazards like air and noise pollution, the spread of infectious diseases, and the social environment (Lalonde, 1974). These factors have harmful effects on health that individuals have little control over (Lalonde, 1974). The health care organization category, which has been defined by Lalonde as the "quantity, quality, arrangement, nature and relationships of people and resources in the provision of health care", has typically taken the forefront to improve health compared to the other health field concept categories (1974). Also identified as the health care system category, health care organization proposes the need for even distribution of these four factors for success of the health care system on a national scale (Lalonde, 1974). Health risks are firmly entrenched in the human biology, lifestyle and environment categories where greater attention to these fields will likely improve the health of Canadians (Lalonde, 1974). Lalonde's health field concept facilitated further research in the public health field including the exploration of environmental health. The World Health 
Organization (2016a) states that environmental health,

addresses all the physical, chemical, and biological factors external to a person, and all the related factors impacting behaviours. It encompasses the assessment and control of those environmental factors that can potentially affect health. it is targeted towards preventing disease and creating health-supportive environments.

A better understanding of interactions within the environmental health field is through the determinants of health. The determinants of health are influential factors in the health field that impact the health of individuals (Health Canada, 1998). These multiple factors stem from the social, physical, and socioeconomic environment, and from behavioural and lifestyle decisions (Health Canada, 1994). Determinants of health such as income, the physical environment, and social health practices are influential factors of health status (Health Canada, 1994). Using the determinants of health, researchers can investigate the interactions of health on specific populations instead of an individual patient (Health Canada, 1994).

To address population related health concerns, Health Canada's taking action on population health (1998) suggests that the population health approach should be used to reduce health inequalities in population groups. The population health approach emphasises the importance of addressing the determinants of health as factors that influence health (Health Canada, 1994). The population health framework emphasizes the importance of everyday interactions that form health outcomes (Dunn and Hayes, 2000). Population health approach defines health as being "a capacity or resource rather than a state" (Health Canada, 1998). Population health contrasts with the traditional view of health where the goal is to improve the health of the population rather than an individual (Health Canada, 1994). Aligning with the same ideology as Lalonde's Health Field Concept, the determinants of health have more recently been aggregated into five categories within the population health framework which include: the social and economic 
environment, the physical environment, personal health practices, individual capacity and coping skills, and health services (Health Canada, 1994). These five categories represent the determinants of health that can be implemented at all levels of government (Health Canada, 1994).

The population health framework promotes action through a bottom-up approach rather than the traditional top-down strategy (Health Canada, 1998). Promoting community involvement and community engagement influences social cohesion and social capital towards improved community health (Health Canada, 1998). Since Lalonde's white paper, public health has changed from a broader approach through addressing the four interdisciplinary health fields to narrowing down health inequalities through the population health approach. The population health approach uses the same principles published in Lalonde's paper while including a broader range of determinants of health as factors likely to affect the health of an individual. Moving forward in public health research the scope has been narrowed to the "new public health" realm where context and composition are the key factors of health, but do not move away from the broader scope of health perspectives. In recent decades, improvements in the healthcare system has been sought out through the Triple Aim framework. The triple aim approach is intended to address three key points: to enhance a patient's experience within the healthcare system, bettering the health of populations, and lessening the per capita cost of care amongst populations (Mery et al., 2017). Although the three goals of this approach are not new in healthcare research, the Triple Aim approach stresses the use of these three goals concurrently to attempt to reduce health inequalities amongst populations (Mery et al., 2017). The next wave of the population health approach has been operationalized in this triple aim procedure. 
Before the "new public health" era was developed, the field of geography was centred around quantitative research through the medical geography field. Historically, research in the medical geography field was divided into two subcategories: the study of disease ecology and the study of disease through spatial variation (Foster, 1987; Eyles, 1993). Both fields stress the importance of health equity (Andrews, 2002). However, health equity of the entire population cannot be addressed without analyzing the effects of the local environment on health. Macintyre, Ellaway, and Cummins (2002) hypothesize the lack of awareness towards the impact of the local environment on health is due to the individualistic view to health. The lack of focus on the impact of the local environment was avoided due to the concern of committing an ecological fallacy (Macintyre et al., 2002). An ecological fallacy is the assumption that interactions made at the individual level can also be applied to aggregated level data (Macintyre et al., 2002). Robinson (1950) first pointed out the significant difference between the same variable at the individual and aggregated level through his explanation of correlated data between individual illiteracy rates of foreign born Americans and illiteracy rates of aggregated to state level in the USA. Research from the 1950s onwards was driven by the individualistic perspective to methodology and concepts in the health field (McKinlay, 1993; Mechanic, 1993). Individualism was fortified in the 1980s where the focus of health was on individual lifestyle rather than local environmental factors (Macintyre et al., 2002). This concept was supported in the developed nations where Margaret Thatcher was quoted saying, "there is no such thing as a society, there are only individuals" (Macintyre et al., 2002). Although research on social constructs have been considered to influence health, research focused heavily on the individualistic approach rather than the environment (Macintyre et al., 2002). From the 1990s onward, the influence of place on health gained importance (Macintyre et al., 2002). The 
transition from medical geography to health geography has been depicted as a shift from medically focused evidence on disease to an interest in wide-ranging models pertaining to social interests and healthcare (Kearns \& Moon, 2002). The importance of place and space was recognized in health geography when researchers critiqued medical geography for lacking to mention the influence of place on health (Luginaah, 2009). Medical geography was centred around the biomedical approach to health heavily favouring quantitative research, whereas health geography emphasises the socioecological approach where place is a central theme (Kearns \& Moon, 2002). Influential factors deriving from place and space functioned at different and multiple scales, was understood to be a significant feature of health geography research (Luginaah, 2009). At this time, the research area labelled as medical geography was modified to health geography (Kearns \& Moon, 2002). This was when health and place was first coined as a concept by Dear and Wolch (1989), where they proposed that the places where human interaction occurs is intertwined with the political, social, and economic constructs which facilitate the role and importance of space (Luginaah, 2009). Place was the focus of research, but data on individuals was based on census surveys collected through an aggregated approach (Macintyre et al., 2002).

The transition from medical to health geography shifted from the individualistic view in health research to the advancement of the "new public health" field (Baum, 1998; Macintyre et al., 2002; Martin \& McQueen, 1989). The new public health perspective emphasized the importance of the physical environment on health and behaviour and challenged researchers to address health inequalities and the factors impacting bad health rather than individualistic explanations to health (Macintyre et al., 2002). Place has been prioritized as an influencer of health by health geography researchers (Luginaah, 2009). Within the new public health field, health is theorized 
by "context" and "composition" (Macintyre et al., 2002). Context are the influential factors in the environment differing for those living within the specified parameters (Macintyre et al., 2002). Context tries to determine whether area is an influential factor on health (Macintyre et al., 2002). Composition are the people living within those parameters (Macintyre et al., 2002). There is still an unanswered narrative of the effects of context on composition within the new public health field.

Health geography in Canada has grown immensely, where Canadian health geographers have begun to research within the realm of the "new public health" field which includes population health (Hayes and Dunn 1998; Hayes 1999), and environmental exposure (Buzzelli et al., 2007; Jerrett et al., 2003). Environmental exposure research, including air pollution on health, has come to integrate socioeconomic status as an important determinant to health status where newer research in exposure assessment and health are observed spatially at finer scales (Buzzelli, 2007). Cohort studies measuring environmental health hazards are often used in research, but some argue that impacts the extent and significance of environmental stressor health effects (Buzzelli, 2007). Observational time-series studies have been the standard type of exposure analysis for the past two decades (Buzzelli, 2007). The newer trend of research on environmental stressors is based on spatial variability and built on networks from multiple monitoring locations (Buzzelli, 2007). Jerrett et al. (2003) also propose that spatial analysis research aims to understand spatial variability of environmental stressors on health. They argue that spatial and temporal methods can contribute to the knowledge of the environment and health (Jerrett et al., 2003). Associations between place and disease suggest spatial characteristics increase the risk of exposure to environmental stressors (Jerrett et al., 2003). Spatial analysis research can further the 
understanding on how context, environmental stressors, affects composition, the population at risk (Jerrett et al., 2003).

Researchers highlight the limitations of solely utilizing the biomedical model of health, stating that progression in the field needs to incorporate both qualitative and quantitative methods (Baxter and Eyles, 1999). The broader inquiry that remains in the field is how can we lessen the risk factors to health that have stemmed from social, environmental, and spatially constructed determinants? (Luginaah, 2009). This has emphasised the importance of addressing geography as a determinant of health.

Acknowledging environment and health as a third subcategory in Canadian geography research would strengthen research in the field as it draws from both policy and empirical based evidence (Eyles, 1997). Environment and health is influenced by many perspectives including the determinants of health framework and health promotion (Eyles, 1997). More broadly, the success and development of the health geography field is heavily reliant on interdisciplinary action and engagement as they can help answer place-specific questions of health (Luginaah, 2009). Using an interdisciplinary approach will also stress the importance of working in a multidisciplinary environment (Luginaah, 2009). However, the progress of research in the health geography field is challenged with the uneven distribution of environmental stressors. Uneven distribution is attributed to context and composition which creates more obstacles in reducing healthcare inequalities (Agyemang et al., 2007; Morello-Frosch et al., 2011; Euteneuer et al., 2014).

From the population health perspective, social gradients in health status measured by socioeconomic factors are persistent in every population (Hayes, 1999). The uneven distribution of environmental stressors can also be explained by the "triple jeopardy" hypothesis. Rosenfield 
(2012) states that race, class, and gender contribute to societal hierarchies. Social gradients are correlated with societal power and can explain health status in populations (Hayes, 1999).

Jerrett et al. (2001) describe the triple jeopardy hypothesis as population groups in society who are disadvantaged whose risks from socioeconomic and behavioural determinants of health increase. Second, they state that these disadvantaged groups are exposed to a greater number of environmental stressors when compared to groups outside the category (Jerrett et al., 2001). Buzzelli and Jerrett state that injustice may be more prevalent in lower health statuses due to greater exposure of environmental stressors (2004). They extend their logic with the triple jeopardy hypothesis stating that health inequalities are found through the social hierarchy (Buzzelli \& Jerrett, 2004). Socially constructed factors in population health have a direct impact on biology highlighting that an individual's place in the social hierarchy often shapes their health outcomes (Hayes, 1999). The Unequal City 2015 provides insight on the current inequalities being experienced in the city of Toronto. The report states that people in lower income groups in the city are unhealthier (Toronto Public Health, 2015). Income status is directly linked to health status, where lower income populations are often the most vulnerable to illness (Toronto Public Health, 2015). Populations of lower socioeconomic status are often exposed to greater levels of environmental pollutants (Clougherty \& Kubzansky, 2009) including higher levels of noise. In recent decades, traffic noise has been found to be associated with higher risk of cardiovascular disease (Munzel et al., 2018). These socially constructed factors affect an individual's immune, nervous, and endocrine system (Hayes, 1999). Noise is a problematic environmental stressor because it affects the body's homeostasis (Babisch, 2011). Noise is also viewed as a deterrent to physiological and psychological health and well-being (Babisch, 2014). In 2014, another study conducted by Babisch et al. (2014) concluded that their results support their hypothesis stating 
that environmental noise is a risk factor for hypertension. The current body of knowledge on noise and cardiovascular disease emphasizes the importance of addressing the health implications of noise. However, the progress and methods of exposure assessment to environmental stressors reaches beyond the scope of this thesis. One of the solutions to reducing excessive noise levels is greenspace in urban areas. Although studies state that greenspace is beneficial for both physiological and psychological health, a few studies have been conducted on the effects greenspace has on socioeconomic status (Mitchell \& Popham, 2008). Like noise, people of higher income status are more likely to use greenspace as a form of physical activity because those of lower income status likely do not live in an environment with accessible greenspace (Mitchell \& Popham, 2008). Evidence shows that elements in the physical environment that promote healthier living can help reduce health inequalities amongst varying population groups (Mitchell \& Popham, 2008).

As a result of the Lalonde's paper and the population health framework, the health promotion framework was created and emphasized the importance of looking at health determinants as factors that can cause sickness (Epp, 1986). The health promotion framework seeks to promote preventative action, rather than to medicate existing conditions for both chronic illnesses and disabilities once they occur (Epp, 1986). The success of the health promotion groups already created focused around fitness, diet, and substance use has led Health Canada to believe that it is a solution that many Canadians are familiarized with already, that can eventually be further integrated into the health care system (Epp, 1986). The health promotion framework encourages community involvement in policy making, while closing the gap on healthcare inequalities amongst population groups (Epp, 1986). 
The health promotion framework benefits Canadians facing social inequalities (Epp, 1986). Using a health promotion approach would reduce the financial burden on a long-term basis for the Canadian healthcare system (Epp, 1986). Healthcare costs at a national level are projected to increase because of the aging population and the increased incidences of disabilities attributed to one or more health determinant (Epp, 1986). Addressing the health inequalities that are associated with population groups at risk should be emphasized (Lalonde, 19740). Social change is a tool that can promote health equality that high-risk populations lack (Lalonde, 1974). Continuing with the health promotion approach by creating new programs stresses the importance of healthy living through preventative action (Epp, 1986).

The challenges in the health field today are not a new phenomenon. This calls for a better understanding of societal interactions and health through the population health approach. Population health focuses on the impact the determinants of health have on population groups. Unlike the traditional medical approach to health, the population health approach is designed to address the healthcare inequalities of the entire population through preventative and precautionary action (Health Canada, 1994). Just like Lalonde's perspective on health, the consideration of the influence of social, economic, and environmental factors on health are important because these determinants affect the quality of life of an individual (Health Canada, 1998). Therefore, and as recognized by the Lalonde White Paper on the health of Canadians as far back as the 1970s, any effort to improve population health must include a concerted effort to address both healthcare access and environmental risk factors (Lalonde, 1974). 


\subsection{Objectives and Research Questions}

The goal of the study is to critically assess the effects of multiple environmental exposures on cardiovascular disease in Toronto. The focus is on the population health determinants that impact the health effects of environmental exposures on cardiovascular disease. The study also aims to understand the individual effects of environmental exposure which individually contribute to the prevalence of hypertension. The long-term study goal is to reduce the level of environmental exposures within Toronto through preventative action and health promotion.

\section{Objectives}

Objective 1. To critically assess the individual exposure effects of environmental stressors on hypertension by controlling for physical, behavioural and socioeconomic stressors

It has been well documented that exposure to environmental stressors are linked to cardiovascular disease. Exposure to excessive noise levels is detrimental to cardiovascular health (Babisch, 2008). A study conducted by Babisch (2011) addresses the concerns of noise exposure due to aircraft and road traffic noise. Babisch (2011) also addresses the effects of biological effects of noise and the disruption to the autonomic nervous system and the endocrine system. The study conducted by Munzel (2014) assesses the implications of road traffic noise on hypertension. Living within close proximity to major roads and arteries has an effect on hypertension (Munzel, 2014). There is still a need to address the effects of noise on hypertension while controlling for physical, behavioural, and socioeconomic stressors. One of the concluding remarks stated by Day (2007) emphasizes that air pollution is spatially attributed. Lower income neighbourhoods are often associated with higher levels of air quality (Day, 2007). The study by Brook et al. (2010) emphasizes the importance of air pollution research and its significance to 
cardiovascular morbidity and mortality. Forester et al. (2014) assess the effects of chronic exposure to air pollution by addressing behavioural and socioeconomic stressors.

Objective 2. To evaluate the effects of multiple environmental exposures on hypertension by controlling for physical, behavioural and socioeconomic stressors

Excessive levels of noise and air pollution are often contributed to major roads and arteries (Forester et al., 2014; Fuks et al., 2011; Tétreault et al., 2013). Vehicles contribute to the to high levels of air and noise pollution (Oiamo, 2014). There is a need for more research that address the effects of multiple environmental exposures. Only a few studies look at both. The few studies that look at both environmental stressors have varying results. The study conducted by Babisch et al. (2014) assesses the effects of multiple exposures on hypertension. The study addresses behavioural and socioeconomic stressors but does not address physical stressors that will be addressed in this study (Babisch et al., 2014). Fuks et al. (2017) assess the effects of both air and noise pollution but only focus on the behavioural and socioeconomic stressors in their study.

Objective 3. To assess the role of greenspace to mitigate environmental stress attributed to excessive noise and air pollution

Evidence shows that exposure to greenspace contributes to lower blood pressure and healthier individuals (Agyemang et al., 2007; World Health Organization 2016b). Greenspace is also seen as a restorative landscape which works as a therapeutic outlet for stress (Hansen et al., 2017; Hansmann et al., 2007; Tyrväinen et al., 2014). Hansmann, Hug, \& Seeland (2007) assess the restorative effects of greenspace. Hansmann et al. (2007) emphasize the importance of greenspace for the promotion of physical activity and stress relief but do not address the singificant effects greenspace has on reducing noise and air pollution. Hansen et al. (2017) state 
the importance of greenspace as a useful tool to reduce exposure to enviornmental pollutants, but do not control for air and noise pollution in their study. Groenewegen et al. (2006) address the societal and behavioural benefits of greenspace but do not mention the environmental benefits of reducing air and noise pollution.

\section{Hypotheses \& Research Questions}

Hypothesis 1 Environmental stressors as measured by air, noise exposure and the availability of greenspace individually account for the effect of the environment on hypertension

Question 1 What are the individual exposure effects of noise, air pollution and greenspace on hypertension on Toronto residents?

Hypothesis 2 Environmental stressors as measured by air, noise exposure and the availability of greenspace cumulatively account for the effect of the environment on hypertension

Question 2 Are there combined effects of multiple environmental exposures?

Hypothesis 3 Physical, behavioural, and socioeconomic stressors contribute to the effect of environmental stressors on cardiovascular health

Question 3 Are the effects of noise, air pollution and greenspace on cardiovascular disease modified by individual stressors? 


\title{
2. Research Manuscript
}

\author{
Abstract \\ This study examines the effects of exposure to ambient noise and air pollution and access to \\ available greenspace on cardiovascular health in Toronto, Ontario. The study is focused around \\ the population health approach which is used to understand the health of the whole population \\ and to reduce health inequalities amongst population groups. The study utilizes population data \\ from the 2012-2014 Canadian Community Health Survey (CCHS), air quality data from 2010- \\ 2014, noise exposure data from 2016, and the DMTI land use parks and recreation data to \\ conduct a logistic regression analysis. The results from the analysis showed significant effects \\ for noise when evaluated individually and measured cumulatively with air pollution and \\ greenspace. Greenspace showed significant results when controlling for behavioural covariates, \\ whereas air pollution displayed conflicting results for acute exposure. Future research on \\ multiple environmental stressors should look to validate the importance of both ambient stressors \\ through a longitudinal study.
}

\subsection{Introduction}

A healthy environment is a right that all people fairly deserve. However, environmental stressors can produce long-term problems, some of which are unavoidable amongst population groups. One important group of stressors is ambient noise and air pollution, both of which are associated with cardiovascular disease (Babisch, 2011; Basner et al., 2014; Brook et al., 2010; Brook \& Kousha, 2015; Forester et al., 2014; Franklin et al., 2015; Fuks et al., 2017; Hammer et al., 2014; Stansfeld, 2015). An increasing amount of evidence shows that the physical environment can also be influential to patient recovery (Blomkvist et al., 2005, Hsu et al., 2010). Akansel \& Kaymakci (2008) also state that patients who have experienced a physiologically disruptive stay 
while in the Intensive care unit (ICU) has been attributed to the overlooked excessive noise levels in hospitals.

With increasing pressures on the improvement of the healthcare system, an approach viewed to be among the most cost-effective options to improve population health to combat premature mortality has been through preventative action, particularly to lessen the quantity of cardiovascular incidences (Health Canada 1994; Health Canada 1998), which is why assessing the prevalence of hypertension is crucial to reduce the number of environmentally related incidences of stress (Sexton, 2012).

Greenspace in neighbourhoods is known to reduce the effects of environmental stressors due to its therapeutic influences (Barton \& Pretty, 2010). Greenspace is also known to be important for a higher quality of life (Barton \& Pretty, 2010; Geoenewegen et al., 2006; Keniger et al., 2013; Tyrväinen et al., 2014; World Health Organization, 2016b). Greenspace has also been show to reduce stress levels (Barton \& Pretty, 2010; Geoenewegen et al., 2006; Keniger et al., 2013; Tyrväinen et al., 2014; World Health Organization, 2016b).

\subsubsection{Environmental Stress}

Stress occurs when an individual's experience with their environment burdens or surpasses their personal ability to cope (Evans \& Cohen, 1982). Evans and Cohen (1982) divide stressors into four distinct categories: cataclysmic events, stressful life events, daily hassles, and ambient stressors (p. 574). Regardless of the category, stressors directly affect the body's homeostasis that is induced by either a psychological or physiological situation (Evans \& Cohen, 1982; Persson \& Zakrisson, 2016; Schneiderman et al., 2005). When a stressful situation is recognised by the body, the sympathetic nervous system as well as endocrine response are triggered, while the parasympathetic nervous system is suppressed (Evans \& Cohen, 1982; Persson \& Zakrisson, 
2016). This stressful event triggers the hypothalamic-pituitary-adrenal (HPA) axis, where the endocrine system releases the corticotrophin-releasing hormone (CRH) from the hypothalamus (Koolhaas et al., 2011; Persson \& Zakrisson, 2016). When the CRH attaches to the receptors of the pituitary gland, adrenocorticotropic hormone (ACTH) is released (Carpenter et al., 2007). ACTH is then secreted from the pituitary glands that triggers the adrenal cortex, producing cortisol, a steroid hormone that regulates the body's stress levels (Evans \& Cohen, 1982; Persson \& Zakrisson, 2016; Spencer \& Deak, 2017). Higher levels of cortisol related to stress caused by the overworking of the HPA axis may be linked to elevated blood pressure levels causing hypertensive incidence (Hamer \& Steptoe, 2012)

\subsubsection{Environmental Exposures and Hypertension}

Hypertension, commonly addressed as high blood pressure, is the most common cardiovascular disease in developed countries, including Canada, that is a also regarded as a global concern (Brook \& Kousha, 2015; Fuks et al., 2011; Poulter et al., 2015). If left untreated, hypertension can increase the risk of stroke, heart failure, or any chronic cardiovascular disease (Robitaille et al., 2012). Exposure to environmental stressors can result in increased incidence of hypertension (Forester et al., 2014; Fuks et al., 2011; World Health Organization, 2013). Traffic-related noise and air pollution is associated with increased blood pressure (Babisch et al., 2014; Fuks et al., 2017; Stansfeld, 2015).

Environmental noise harms the psychological and physiological health of the body, disturbs the autonomic nervous system and endocrine system, which alters the body's homeostasis (Babisch, 2011; Babisch et al., 2014; Hammer et al., 2014; Tétreault et al., 2013). When the body is subjected to elevated noise levels, the HPA axis is activated where it reads noise as a stressinduced event and releases cortisol (Spreng, 2000). Exceeding the daytime noise requirements of 
65 decibels $(\mathrm{dB})$ is associated with elevated blood pressure levels and higher levels of stress (Babisch, 2008), which can lead to more serious cardiovascular diseases and increased rates of mortality (Babisch, 2008; Babisch 2014; Basner et al., 2014; Evans \& Cohen, 1982; Forester et al., 2014; Munzel et al., 2018; Stansfeld, 2015). Elevated levels of noise cause noise annoyance which contributes to sleep disturbance and sleep apnea, which has been regarded as a risk factor to hypertension. (Babisch, 2011; Basner et al., 2014; Hammer et al., 2014; Stansfeld, 2015).

Blood pressure levels are lower at night, which makes the body more sensitive to increased noise levels while at rest (Hammer et al., 2014). Noise levels that exceed recommended limits increase heart rate levels, while simultaneously boosting the amount of stress hormones released (Hammer et al., 2014). The involuntary arousals of the autonomic system, such as the activation of the sympathetic nervous system, is associated with increased blood pressure and cortisol levels (Hammer et al., 2014; Munzel et al., 2014; Munzel et al., 2018).

Exposure to air pollutants has a similar health risk noise pollution has but affects the body in a physiological way by causing oxidative stress, inflammation, and atherosclerosis (Brook et al., 2004; Forester et al., 2014; Fuks et al., 2017; Newby et al., 2015). Acute exposure to air pollution has been correlated with higher blood pressure levels, which can lead to more serious chronic cardiovascular disease or premature mortality (Brook et al., 2010; Brook \& Kousha, 2015; Forester et al., 2014; Franklin et al., 2015; Fuks et al., 2017). In the event an individual is exposed to an ambient pollutant, oxidative stress can occur on the surfaces of the lungs, where phagocytes exist which are responsible for absorbing bacteria potentially harmful to the body (Newby et al., 2015). Acute exposure in cities known to have lower concentrations of air pollutants has been found to create "clinically meaningful" outcomes leading to hypertensive results (Brook \& Kousha, 2015; Franklin et al., 2015). Air pollution is not distributed evenly 
amongst populations, suggesting the need to assess the associations between place and health effects (Day, 2007; Hazlehurst et al., 2018; Koubi 2016).

\subsubsection{Multiple Exposures}

There is a shortage of studies that assess the relationship between noise and air pollution and their combined effects on hypertension (Allen \& Adar, 2011; Babisch et al., 2014; Davies et al., 2009; de Kluizenaar et al., 2013; Tétreault et al., 2013). In the urban context the pollutants are correlated (Forester et al., 2014; Oiamo, 2014; Tétreault et al., 2013). The unanswered question to date is whether multiple environmental stressors are additive or multiplicative (Evans \& Cohen, 1982), and whether there is a plausible solution to reduce the level of exposure to these environmental stressors to reduce the number of individuals being exposed to these pollutants. Greenspace may provide a solution to reduce the level and impact of noise and air pollutants in an urban setting.

Both types of environmental stressors have been often related to traffic volume and density (Allen \& Adar, 2011; Davies et al., 2009; Forester et al., 2014; Fuks et al., 2011; Fuks et al., 2017; de Kluizenaar et al., 2013; Oiamo, 2014; Stansfeld, 2015; Tétreault et al., 2013). Those living in proximity to major roads and arteries are exposed to higher levels of air pollution (Brauer et al., 2002). Babisch (2011) states that excessive noise levels from transportation has been heavily documented which is linked to hypertension. Non-exhaust emissions including brake wear, tyre wear, and abrasion from road surfaces also contribute to poorer air quality levels (Thorpe \& Harrison, 2008). Point source pollutants are still able to affect air quality even in cities that may not be heavily industrialized (Oiamo et al., 2015). Geographic location is a key contributor to ambient exposure to pollutants likely increasing the prevalence of hypertension (Black et al., 2012; Euteneuer et al., 2014; Hollingworth et al., 2016; Poulter et al., 2015). 


\subsubsection{Greenspace}

Greenspace helps to reduce exposure to environmental exposures, while promoting physical community interaction and unity (Agyemang et al., 2007; Barton \& Pretty, 2010; Jenerette et al., 2011; Keniger et al., 2013; World Health Organization, 2016b). Greenspace also improves mental health and wellness, which can lead to an improvement of coping abilities with stressful situations as it positively influences both the physiological and psychological state of an individual (Barton \& Pretty, 2010; Dean et al., 2011; Geoenewegen et al., 2006; Keniger et al., 2013; World Health Organization, 2016b). Therapeutic landscapes, like greenspace, provide physical, mental, and spiritual healing in ways a built environment cannot provide (Day, 2007; Gatrell \& Elliott, 2009; Kearns \& Gesler, 1998). For example, the Japanese tradition of ShinrinYoku (forest bathing), engaging oneself in nature while consciously using the five senses, has been recognized as therapeutic with positive health benefits (Hansen et al., 2017). Research shows that simply observing nature can reduce stress levels (Barton \& Pretty, 2010; Geoenewegen et al., 2006; Tyrväinen et al., 2014), which aligns with both Kaplan's Attention Restoration theory and Ulrich's Stress Reduction theory (Hansen et al., 2017; Hansmann et al., 2007). Numerous studies show that immersing oneself in nature has a profound effect on the sympathetic nervous system, which controls the body's "fight-or-flight" response, by suppressing it and ultimately lowering blood pressure and cortisol levels (Berman et al., 2008; Gladwell et al., 2012; Hansen et al., 2017; Tyrväinen et al., 2014).

This study attempts to understand the effects of mulitple environmental exposures on cardiovascular disease by addressing the indepdent effects of air pollution, noise and greenspace on hypertension. Furthermore, the study also seeks to address the combined effects of multiple environmental exposures by measuring all individual variables while controlling for variables that could have a potential confounding effect on hypertension. 


\subsection{Methods}

\subsubsection{Study Area}

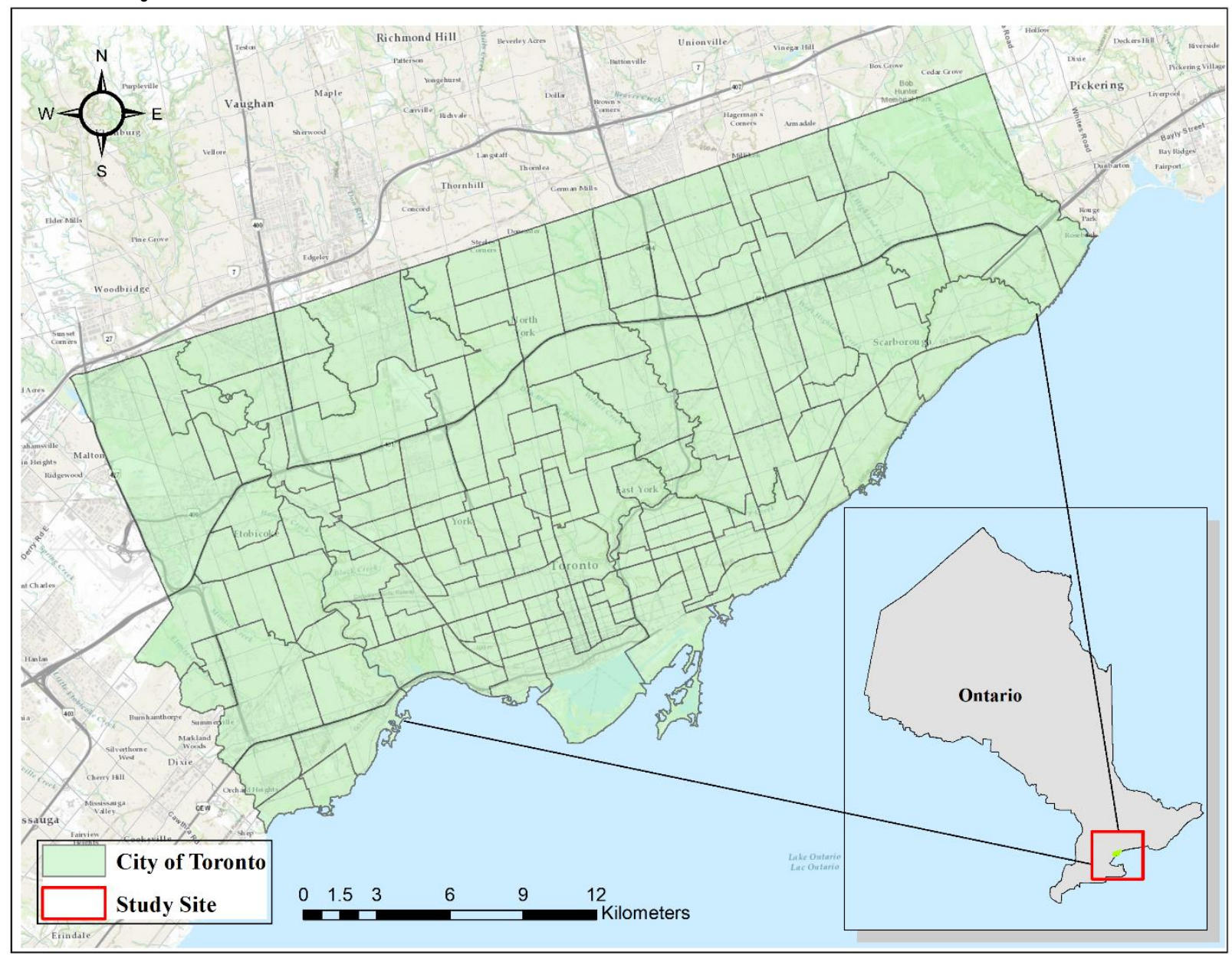

Figure 1 The study site map of the city of Toronto

The study was conducted in Toronto, Ontario (Figure 1), the largest city in Canada, the city covers a land area mass of $630 \mathrm{~km}^{2}$, with a population of 2.730,500 (Statistics Canada, 2016b). The Greater Toronto Area (GTA), includes Mississauga, Vaughn, and Pickering, adjacent to the northwestern shoreline of Lake Ontario, and is one of the largest metropolitan areas of Canada, Toronto has three expressways: The Don Valley Parkway, running north-southbound; The Gardiner Expressway, running east-westbound; and The William R. Allen Road, running northsouthbound. Several provincial highways also run through Toronto, including the busiest 
highways in the province, highway 401. Toronto is a diverse city in terms of environment, and residents are exemplified by the identification of the 140 different neighbourhoods. The Unequal City 2015 report published by Toronto Public Health concludes the significant differences between income groups in the city of Toronto stating that unequal opportunities for healthier living still exists (2015). Toronto continues to lack in health equality where many residents are still disadvantaged due to their socioeconomic status (Toronto Public Health, 2015). Health inequalities amongst lower income groups often coincide with the determinants of health (Toronto Public Health, 2015). In addition to the socioeconomic inequalities amongst population groups, Toronto is faced with challenges that might defeat reductivity process of air pollution, a process that has reduced since the mid 1900s. Reductive processes are confronted with rapid population and vehicular usage (Ewing et al., 2014). As traffic increases along with urban development and population growth, so does the exposure levels of noise pollution, as individuals are exposed daily to levels of noise that can affect cardiovascular health (Babisch, 2014).

\subsubsection{Analytic Framework}

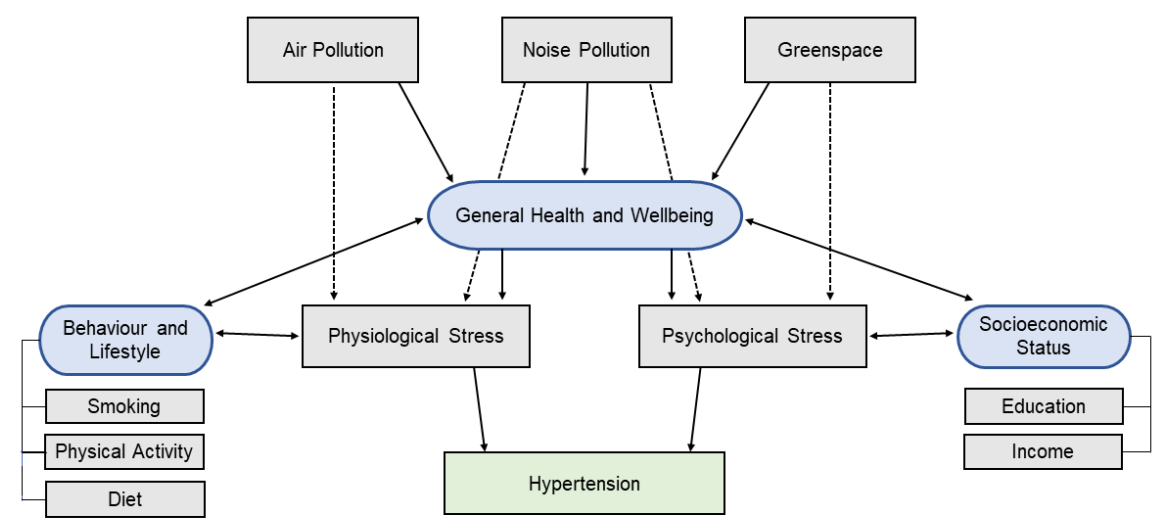

Figure 2 Framework of proposed health effects of environmental stressors 
The objective of the study seeks to understand how exposure to multiple environmental stressors affects hypertensive prevalence, and to assess whether accessibility to greenspace reduces affects of noise and air pollution. The relationship between traffic related noise and air pollution is suggested to work cumulatively as they are often found together, however, there is a lack of understanding as to whether these two pollutants are confounding or interactive (Tétreault et al., 2013). Additionally, the World Health Organization has identified the importance of addressing behavioural and socioeconomic risk factors of hypertension (2013). Behavioural risk factors are often influenced by an individual's living conditions and working environment which can increase the prevalence of physiological stress (Adler et al., 2000; World Health Organization, 2013). Socioeconomic status can influence behavioural and lifestyle choices through unhealthy diets, overconsumption of alcohol and the lack of physical activity (Adler et al., 2000), while affecting an individual's psychological stress levels through fear of unemployment, which may induce hypertensive development (World Health Organization, 2013).

\subsubsection{Population Data}

The study uses Statistics Canada's Canadian Community Health Survey (CCHS) 2012 and combined 2013/2014 datasets for respondents ages 18 years of age and older. The CCHS is a voluntary cross-sectional designed survey collected annually that gathers information related to health care utilization, health status and determinants of health (Statistics Canada, 2016a). Since 2001, results of the CCHS are published annually at the microdata level primarily for population health usage (Statistics Canada, 2016a). Respondents are contacted directly through computer assisted software or by telephone interviews with questions optioned for English or French or translated to the language of the respondent's choice when necessary (Statistics Canada, 2016a). 
The application process to obtain access to CCHS microdata at the Research Data Centre (RDC) was through the Social Science and Humanities Research Council (SSHRC)

The first category of covariates from the CCHS dataset controlled for the demographic variables sex and age. Sex was coded as a binary variable with the female reference coded as the outcome of interest. Age was categorized into four classes ( $<=45,46-55,56-65, \& 66+)$. Below forty-five was determined as the reference value because hypertension is less likely to be prevalent in younger individuals (Kluizenaar, 2015).

The study also assessed the influence of the socioeconomic covariates education and income on hypertensive prevalence. Among those variables were education and income. The education variable was recoded into a binary outcome, with high school or less being the response of interest. Education is one of the social determinants that is viewed as a risk factor for developing hypertension (World Health Organization, 2013). The income variable was based off the total household income and recoded categorically with the reference category being those earning $\$ 100,000+$ or more. The categories were determined based on approximate low-income cut-off ratio based on data available in the CCHS dataset. Income is a social determinant variable that can have an effect on the respondent's stress levels, potentially due to the stress of the lack of financial stability which can lead to hypertensive incidences (World Health Organization, 2013).

The study also assessed the influence of behavioural and lifestyle choices as measured by daily cigarettes smoked, physical activity index, and daily consumption of fruits and vegetables were assessed. Smoking was recoded into a binary variable where the daily smoker response was used as the outcome of interest. In addition to respiratory illness and cancer, Scallan et al., (2010) state that smoking can also cause arterial stiffness which can lead to elevated level of blood pressure and oxidative stress through endothelial dysfunction. The Physical Activity Index variable is 
based off the respondent's leisure time calculated by their total daily Energy Expenditure (kcal/kg/day) based off of the list of activities provided by the CCHS (Statistics Canada, 2011). The respondents were recoded as a binary variable where "active" or "inactive" were used. The respondent was deemed "inactive" if the individual's EE was below a value of 3 . The respondents were not asked the level of intensity of their activity by which the CCHS categorized all activities as "low intensity" (Statistics Canada, 2011). The daily consumption of fruits and vegetables was recoded as a binary variable with less than 5 fruits and vegetables per day as the outcome of interest. The World Health Organization recommends consuming five servings of fruits and vegetables per day, such as potassium-rich produce known to reduce blood pressure levels, to maintain a healthy lifestyle, and to reduce the risk of a hypertensive diagnosis (2013).

The final category of variables assessed the general health and wellbeing of a respondent, where perceived health and overall stress of the respondent's life were evaluated. The CCHS separated the responses into five categories (poor, fair, good, very good, excellent). The perceived health variable was recoded to correspond to a binary response, fair/poor being the outcome of interest. Perceived health is an indication of the respondent's own judgment and perception of their health (Statistics Canada, 2011). Rating of self-perceived health is beneficial for determining potential health inequalities of a population (European Commission, 2016), a recommended variable from the World Health Organization's "World Health Survey" of 2002, to incorporate into questionnaires. The life stress variable was recoded as a binary variable with the answer quite $a$ bit/extremely as the response of interest. The CCHS separated the responses into five categories (not at all stressful, not very stressful, a bit stressful, quite a bit stressful, extremely stressful). Overall life stress can be a determinant and an important factor in identifying hypertension. A 
respondent's perception on their overall stress in life can indicate their general well-being and overall satisfaction of their environment (Ames et al., 2001).

\subsubsection{Environmental Exposure Variables}

Noise level assessments were conducted to measure the sound levels within the city of Toronto. The measurement period was conducted within a one-week monitoring span to collect a series of noise levels at varying times of a single day, using a Noise Sentry RT sound level meter which can measure both A and C weighted sound pressure levels (Oiamo et al., 2017). Noise measurements were sampled over the period of August to October 2016 where a total of 220 noise monitors were used to monitor the A-weighted decibel scale (Oiamo et al., 2017). Aweighted measurement is a more accurate representation of the sound levels humans can perceive (Oiamo et al., 2017). The sites were determined based on the suggested locations coming from the city of Toronto's advisory committee who recommended settings based on land use (residential, open space, employment), road type (arterial, collector), and sites of interest (schools, concert venues, hospitals) (Oiamo et al., 2017). The monitors were attached to hydro or light poles to the closest designated geocoded location (Oiamo et al., 2017). Measurements were taken for the full week, weekend, and weekdays along with the 24-hour average, daytime, and nighttime noise levels (Oiamo et al., 2017). 24-hour traffic noise levels were used in the study, where the reference category was less than or equal to 51 decibels.

Air quality measurements were from an annual average concentrations of Nitrogen Dioxide ( $\left.\mathrm{NO}_{2}\right)$ from 2010-2014, derived and based off the National Air Pollution Surveillance (NAPS) Network of 2006 (Environment Canada, 2008), using 134 monitors (Hystad et al., 2011). $\mathrm{NO}_{2}$ was monitored continuously in parts per billion (ppb) by 1 hour means (Environment Canada, 2008), based off satellite atmospheric composition data at a $10 \times 10 \mathrm{~km}$ resolution (Hystad et al., 
2011). The land use regression method has been used at length to predict city levels of nitrogen dioxide $\left(\mathrm{NO}_{2}\right)$ and calculated geographically to test for spatial influences using an estimate of 50m to 50km buffer distance to NAPS monitor sites (Hystad et al., 2011). Linear pollution gradients were determined by the use of NAPS monitors in the study, calculated based on their distance to nearest roads and highways using the DMTI road network data, while also being representative of Canadian conditions (Hystad et al., 2011). To assess the validity of the $\mathrm{NO}_{2}$ concentration accuracy, a bootstrap approach was used for the land use regression model to test for the model's sensitivity and monitor parameters (Hystad et al., 2011). The land use regression model then tested the "leave-one-out" approach to determine the predicted values for an excluded monitor (Hystad et al., 2011). The final assessment tested $\mathrm{NO}_{2}$ LUR models both with and without the determined gradients (Hystad et al., 2011).

The greenspace assessment was based on publicly accessible land use data from (DMTI Spatial Inc., 2012) grouped into separate categories to display nationwide topographic urban data. The category that was used in this study was the parks and recreation vector file. The greenspace variable used in the study was coded as a binary outcome whether a respondent has less than one hectare (ha) of green space within a 200m buffer radius from their residence. Natural England (2010) recommends 2 hectares of green space within a 300m distance from home, but the European Common Indicators suggests living within a 15-minute walk from publicly accessible green space (World Health Organization, 2016b). There is no definitive description of the size of green space suggested to reduce health concerns, and every municipality varies in description and funds allocated towards Parks \& Recreation (Evergreen, 2004). One hectare of green space was chosen because of the difficulty for some residents to access more than two hectares of 
green space in a highly urbanized and populated city like Toronto, and the decreasing trend to provide residents with new green space (Evergreen, 2004).

The ratio of the number of respondents who live within a $200 \mathrm{~m}$ distance from the closest area of greenspace was created within ArcMap 10.5.1. First, the DMTI parks and recreation shapefile was clipped to the city of Toronto's boundary file and projected to the North American Datum $17 \mathrm{~N}$. Next, a buffer of $200 \mathrm{~m}$ was created based on each respondent's postal code within the city of Toronto. The area of the buffered greenspace in hectares was used. Additionally, the area of greenspace was calculated by dividing the total area of the buffer. The greenspace data was joined to the CCHS 2012, and 2013/2014 dataset based on respondent postal code addresses.

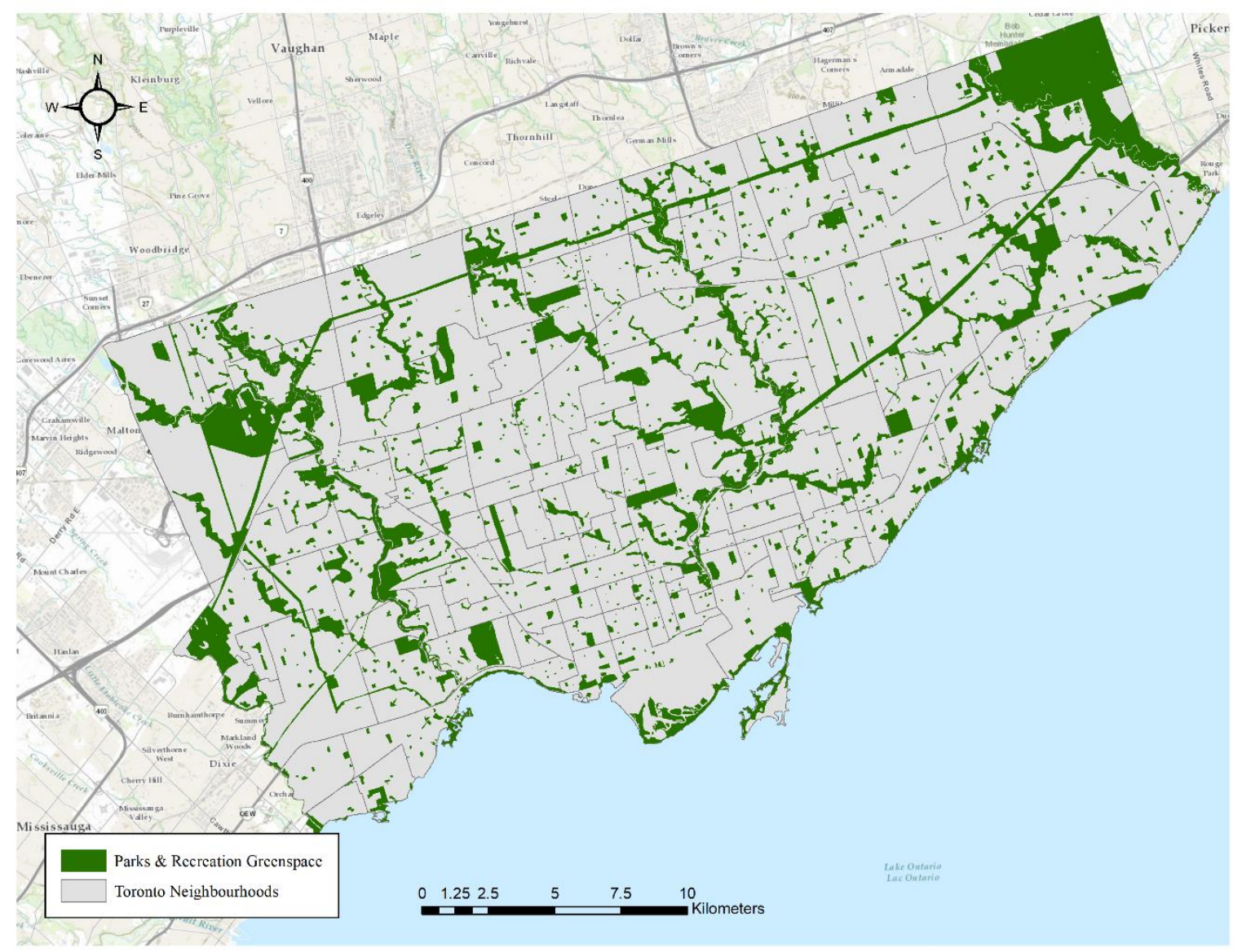

Figure 3 The greenspace map of parks and recreation areas in the city of Toronto 


\subsubsection{Analyses}

First, the environmental exposures for both noise and air pollution were ran, where a Bivariate (Pearson) Correlation was conducted to determine the relationship between the exposure of interest and the outcome variable of interest. Descriptive statistics on the distribution and frequencies of each environmental exposure and the variable of interest was also conducted. A correlation matrix between the categorical covariates used in the final model was created to determine the pairwise chi-squared values of each variable. A logistic regression analysis was conducted to determine the effect exposure to noise pollution, air pollution, and greenspace had on hypertension. Logistic regression is useful for finding the best fitting model to describe the relationship between the binary characteristic of interest and the set of individual exposure variables being used in this study. Next, four logistic regression models were created and were adjusted for the noise pollution, air pollution, and area of greenspace. Model 1 was adjusted for the demographics variables, age and sex. Model 2 was adjusted for the socioeconomic variables, income and education. Model 3 was adjusted for behaviour and lifestyle variables, smoking, physical activity, and diet. Model 4 was adjusted for stress variables including self-rated health, and overall life stress. One multiple exposure model was created to address the possibility of determining whether the 24-hour traffic noise had an interacting effect on the nitrogen dioxide zscore variable. The diagnostics of each model were recorded, where the $\mathrm{R}^{2}$ values, the classification accuracy, and the Hosmer-Lemeshow goodness-of-fit were all logged. The models were then bootstrapped to measure the study's accuracy, while addressing the variability of the sample used. Bootstraps were used for all models where the $95 \%$ confidence intervals were recorded for 1,000 samples from the CCHS total dataset. 


\subsection{Results}

\subsubsection{Population Data Descriptives}

Table 1 shows the descriptive statistics from the CCHS 2012/2013/2014 dataset on the number of respondents affected by hypertension as well as the covariates chosen. The total number of respondents who did not report hypertension was 79.5\%. More females reported hypertension $(57.55 \%)$ and the proportion of respondents with hypertension increased with age. Respondents who were 45 years of age and younger reported the lowest hypertension rates (8.53\%) in contrast to respondents 66 years of age with the highest prevalence of hypertension at 57.09\%. Hypertension was more prevalent for respondents who reported to only have a high school diploma or less. Respondents who reported hypertension also reported to have made less than $\$ 40,000$ (44.98\%). Respondents who reported to smoking cigarettes daily also reported hypertension (29.56\%). It was observed that $61.17 \%$ of respondents who reported to be physically inactive also reported hypertension. Respondents who reported hypertension reported to having fair/poor perceived health $(64.41 \%)$.

An ANOVA between the $\mathrm{NO}_{2}$ variable and the categorical variables in the model was conducted (table 2). There was a statistically significant difference between the greenspace and 24-hour traffic noise variables. A statistically significant difference in nitrogen dioxide concentrations between income groups was also observed. Different age groups also had statistically significant differences in nitrogen dioxide levels. 
Table 1 Descriptive table of the variables used from the CCHS 2012 \& 2013/2014 dataset

\begin{tabular}{|c|c|c|c|c|c|}
\hline & & \multicolumn{3}{|l|}{ Hypertension } & \multirow{3}{*}{ Chi-square } \\
\hline & & NO (79.5\%) & YES $(20.5 \%)$ & Total & \\
\hline & & $\mathbf{N} \%$ & $\mathbf{N} \%$ & $\mathbf{N} \%$ & \\
\hline Parks and Recreation space & Less than $1 \mathrm{Hc} 200 \mathrm{~m}$ & $\mathbf{7 5 . 3 7 \%}$ & $77.39 \%$ & $75.8 \%$ & 1.9 \\
\hline \multirow[t]{2}{*}{ Sex } & MALE & $43.33 \%$ & $42.45 \%$ & $43.2 \%$ & 0.28 \\
\hline & FEMALE & $56.67 \%$ & $\mathbf{5 7 . 5 5 \%}$ & $56.8 \%$ & \\
\hline \multirow[t]{4}{*}{ Age } & $<=45$ & $56.04 \%$ & $8.53 \%$ & $46.3 \%$ & $1000.08 * *$ \\
\hline & $46-55$ & $12.97 \%$ & $12.23 \%$ & $12.8 \%$ & \\
\hline & $56-65$ & $13.93 \%$ & $22.15 \%$ & $15.6 \%$ & \\
\hline & $66+$ & $17.06 \%$ & $\mathbf{5 7 . 0 9 \%}$ & $25.3 \%$ & \\
\hline \multirow[t]{2}{*}{ Education } & High School or Less & $40.23 \%$ & $47.54 \%$ & $41.7 \%$ & $18.88 * *$ \\
\hline & 100,000 OR MORE & $28.62 \%$ & $16.24 \%$ & $26.1 \%$ & \\
\hline \multirow[t]{3}{*}{ Income } & $70,000-100,000$ & $15.12 \%$ & $12.30 \%$ & $14.5 \%$ & $108.23 * *$ \\
\hline & $40,000-70,000$ & $25.85 \%$ & $26.48 \%$ & $26.0 \%$ & \\
\hline & LESS THAN 40,000 & $30.41 \%$ & $44.98 \%$ & $33.4 \%$ & \\
\hline Smoked Cigarettes Daily & YES & $19.42 \%$ & $29.56 \%$ & $21.5 \%$ & $52.29 * *$ \\
\hline Physical activity Index & INACTIVE & $44.89 \%$ & $61.17 \%$ & $48.2 \%$ & $91.06 * *$ \\
\hline \multicolumn{2}{|c|}{ Daily consumption of fruits/veg LESS THAN 5 PER DAY } & $60.54 \%$ & $64.60 \%$ & $61.4 \%$ & $5.97 *$ \\
\hline Perceived Health & FAIR/POOR & $35.81 \%$ & $64.41 \%$ & $41.7 \%$ & $288.73 * *$ \\
\hline Life Stress & QUITE A BIT/EXTREMELY & $22.79 \%$ & $22.98 \%$ & $22.8 \%$ & 0.02 \\
\hline
\end{tabular}

The bivariate relationships between the categorical variables which were tested with the Chi Square statistic (Table 3). Physical activity was related to life stress, perceived health and daily consumption of fruits and vegetables. Income and highest degree obtained also displayed statistical relationships with the behavioural and lifestyle variables and the stress variables. The demographic variables, age and sex, had statistically significant relationships between the 
behavioural and stress covariates. Accessibility to greenspace did not display statistically significant relationships between the other categorical variables aside from physical activity. The 24-hour traffic noise was independent of most variables but displayed strong statistical relationships between the stress and behavioural covariates.

Table 2 ANOVA comparing categorical variables with NO2

\begin{tabular}{|c|c|c|c|c|c|c|}
\hline Nitrogen Dioxide $\left(\mathrm{NO}_{2}\right)$ & & Sum of Squares & df & Mean Square & $\mathbf{F}$ & Sig. \\
\hline \multirow[t]{3}{*}{ Less than 1 hectare within $200 \mathrm{~m}$} & Between Groups & 549.523 & 1503 & 0.366 & 3.353 & $0.000 * * *$ \\
\hline & Within Groups & 406.576 & 3729 & 0.109 & & \\
\hline & Total & 956.099 & 5232 & & & \\
\hline \multirow[t]{3}{*}{ leq24-Tr } & Between Groups & 3882.065 & 1503 & 2.583 & 3.269 & $0.000 * * *$ \\
\hline & Within Groups & 2946.657 & 3729 & 0.790 & & \\
\hline & Total & 6828.722 & 5232 & & & \\
\hline \multirow[t]{3}{*}{ Age } & Between Groups & 2793.759 & 1503 & 1.859 & 1.252 & $0.000 * * *$ \\
\hline & Within Groups & 5535.743 & 3729 & 1.485 & & \\
\hline & Total & 8329.502 & 5232 & & & \\
\hline \multirow[t]{3}{*}{ Sex } & Between Groups & 367.081 & 1503 & 0.244 & 0.994 & 0.557 \\
\hline & Within Groups & 916.609 & 3729 & 0.246 & & \\
\hline & Total & 1283.690 & 5232 & & & \\
\hline \multirow[t]{3}{*}{ Income } & Between Groups & 2806.494 & 1499 & 1.872 & 1.526 & $0.000 * * *$ \\
\hline & Within Groups & 4490.827 & 3660 & 1.227 & & \\
\hline & Total & 7297.321 & 5159 & & & \\
\hline \multirow[t]{3}{*}{ Highest Degree Obtained } & Between Groups & 397.514 & 1503 & 0.264 & 1.128 & $0.002 *$ \\
\hline & Within Groups & 874.159 & 3729 & 0.234 & & \\
\hline & Total & 1271.673 & 5232 & & & \\
\hline \multirow[t]{3}{*}{ Smoked Cigarettes Daily } & Between Groups & 255.973 & 1503 & 0.170 & 1.014 & 0.368 \\
\hline & Within Groups & 626.032 & 3729 & 0.168 & & \\
\hline & $\begin{array}{l}\text { Total } \\
\text { Between Groups }\end{array}$ & $\begin{array}{l}882.005 \\
398.845\end{array}$ & $\begin{array}{l}5232 \\
1503\end{array}$ & 0.265 & 1.090 & $0.022 *$ \\
\hline \multirow{2}{*}{ Physical activity Index } & Within Groups & 907.734 & 3729 & 0.243 & & \\
\hline & Total & 1306.579 & 5232 & & & \\
\hline \multirow[t]{3}{*}{ Daily consumption of fruits/veg } & Between Groups & 365.191 & 1503 & 0.243 & 1.034 & 0.215 \\
\hline & Within Groups & 875.974 & 3729 & 0.235 & & \\
\hline & Total & 1241.165 & 5232 & & & \\
\hline \multirow[t]{3}{*}{ Perceived health } & Between Groups & 368.617 & 1503 & 0.245 & 1.013 & 0.384 \\
\hline & Within Groups & 903.224 & 3729 & 0.242 & & \\
\hline & $\begin{array}{l}\text { Total } \\
\text { Between Groups }\end{array}$ & $\begin{array}{r}1271.840 \\
272.849\end{array}$ & $\begin{array}{l}5232 \\
1503\end{array}$ & 0.182 & 1.042 & 0.170 \\
\hline \multirow{2}{*}{ Life stress } & Within Groups & 649.806 & 3729 & 0.174 & & \\
\hline & Total & 922.655 & 5232 & & & \\
\hline
\end{tabular}

$* p<0.05, * * p<0.01, * * * p<0.001$ 
Table 3 Chi-square matrix between categorical variables

\begin{tabular}{|c|c|c|c|c|c|c|c|c|c|c|c|}
\hline & & 1 & 2 & 3 & 4 & 5 & 6 & 7 & 8 & 9 & 10 \\
\hline 1 & Life stress & & & & & & & & & & \\
\hline 2 & $\begin{array}{l}\text { Perceived } \\
\text { health }\end{array}$ & $61.87 * * *$ & & & & & & & & & \\
\hline 3 & $\begin{array}{l}\text { Daily } \\
\text { consumption of } \\
\text { fruits/veg }\end{array}$ & 0.34 & $56.215^{* * *}$ & & & & & & & & \\
\hline 4 & $\begin{array}{l}\text { Physical } \\
\text { activity Index }\end{array}$ & $9.27 *$ & $289.155^{* * * *}$ & $172.520 * * *$ & & & & & & & \\
\hline 5 & $\begin{array}{l}\text { Smoked } \\
\text { Cigarettes } \\
\text { Daily }\end{array}$ & 0.47 & 0.399 & 0.013 & 3.023 & & & & & & \\
\hline 6 & $\begin{array}{l}\text { Highest Degree } \\
\text { Obtained }\end{array}$ & $25.998 * * *$ & $77.685^{* * *}$ & $22.564 * * *$ & $41.025 * * *$ & $28.421 * * *$ & & & & & \\
\hline 7 & Income & $12.646^{* *}$ & $290.147 * * *$ & $20.604 * * *$ & $139.459 * * *$ & $11.556^{* * *}$ & $415.002 * * *$ & & & & \\
\hline 8 & Sex & 2.264 & $4.077 *$ & $82.283 * * *$ & $15.920 * * *$ & $20.292 * * *$ & 0.913 & $56.648 * * *$ & & & \\
\hline 9 & Age & $75.302 * * *$ & $226.586^{* * *}$ & 2.667 & $49.203 * * *$ & $246.123^{* * *}$ & $99.068 * * *$ & $272.676 * * * *$ & $20.168 * * *$ & & \\
\hline 10 & $\begin{array}{l}\text { Less than } 1 \\
\text { hectare within } \\
200 m\end{array}$ & 0.025 & 0.228 & 2.824 & $5.119^{*}$ & 3.571 & 0.518 & 1.346 & 0.020 & 2.861 & \\
\hline 11 & leq24_Tr & 3.140 & $19.793 * * *$ & $17.579 * * *$ & $25.550 * * *$ & 3.786 & 5.741 & 282.159 & $7.986^{*}$ & 12.832 & $11.370 *$ \\
\hline
\end{tabular}

\subsubsection{Environmental Exposures}

Table 4 Descriptive statistics for environmental exposures

\begin{tabular}{|c|c|c|c|c|}
\hline Hypertension & & $\mathrm{NO}_{2}(\mathrm{ppb})$ & $\begin{array}{l}\text { Leq24h Traffic } \\
\text { (dBA) }\end{array}$ & Greenspace $200 \mathrm{~m}$ \\
\hline \multirow[t]{3}{*}{ NO } & Mean & 17.54 & 56.85 & 0.06 \\
\hline & Median & 17.28 & 55.00 & 0.00 \\
\hline & Std. Deviation & 3.04 & 7.92 & 0.11 \\
\hline \multirow[t]{3}{*}{ YES } & Mean & 17.48 & 57.53 & 0.06 \\
\hline & Median & 17.10 & 56.00 & 0.00 \\
\hline & Std. Deviation & 3.26 & 7.95 & 0.11 \\
\hline \multirow[t]{3}{*}{ Total } & Mean & 17.52 & 56.99 & 0.06 \\
\hline & Median & 17.25 & 55.00 & 0.00 \\
\hline & Std. Deviation & 3.08 & 7.93 & 0.11 \\
\hline \multirow[t]{2}{*}{ Hypertension ANOVA } & $\mathrm{F}$ & 0.34 & 6.43 & 0.34 \\
\hline & Sig. & 0.56 & $0.01 * *$ & 0.56 \\
\hline
\end{tabular}


Respondents who reported hypertension also reported to have less than 1 hectare of greenspace within a 200m distance of their residence (77.39\%). Respondents who did not report hypertension also reported to have less than 1 hectare of greenspace within a 200m distance of their residence (75.37\%). Respondents who reported hypertension were exposed to $\mathrm{NO}_{2}$ on an average of $17.48(\mathrm{ppb}), 57.53 \mathrm{~dB}(\mathrm{~A})$ of 24-hour traffic noise, with a distance ratio of 0.06 (Table 4).

The distribution of 24-hour traffic noise levels in the city of Toronto by census tract is presented in figure 4. Noise levels exceeded the recommended limit of $55 \mathrm{~dB}$ in most census tracts displayed in figure 4. Higher noise levels in Toronto was observed throughout the central corridor of the city. Elevated levels along major expressways and corridors, the downtown core and densely populated areas were also observed.

The distribution of $\mathrm{NO}_{2}$ in Toronto by census tracts is presented in figure 5. Lower levels of $\mathrm{NO}_{2}$ was observed along the eastern side of Toronto. Higher levels of $\mathrm{NO}_{2}$ was dispersed unevenly throughout the city census tracts. The "U" shape often observed with variables typically seen variables observing socioeconomic and environmental inequality in Toronto was apparent.

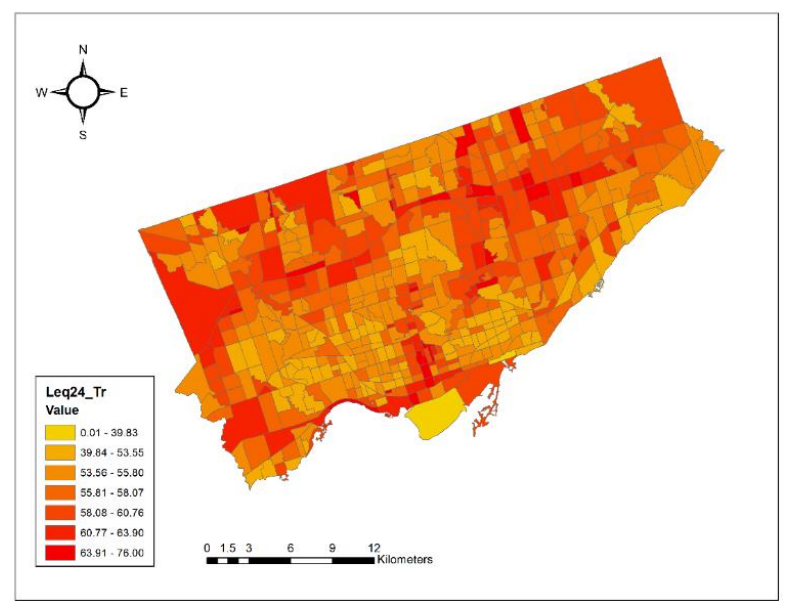

Figure 4 Map of 24-hour traffic noise distribution in the city of Toronto by census tract 


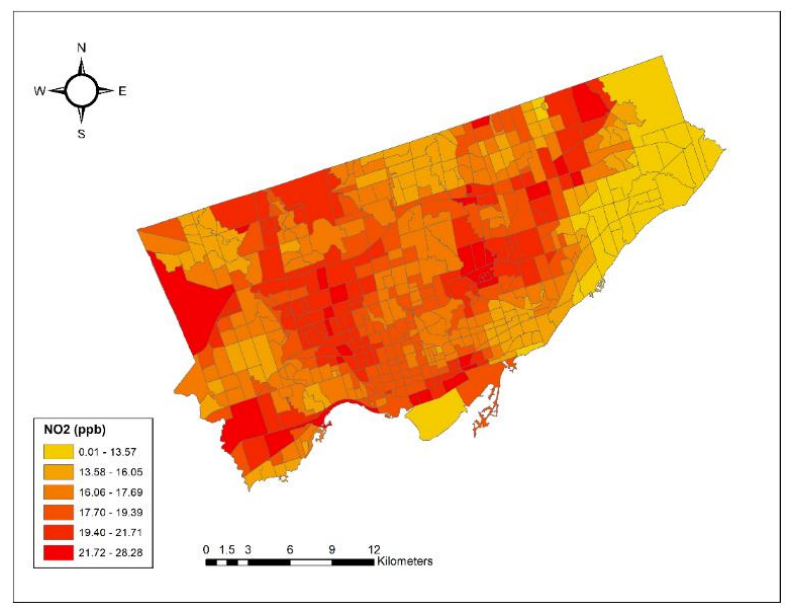

Figure 5 Map of Nitrogen Dioxide $\left(\mathrm{NO}_{2}\right)$ distribution in the city of Toronto by census tract

\subsubsection{Multivariate Modelling Results}

Table 5 Logistic regression of noise effects on hypertension

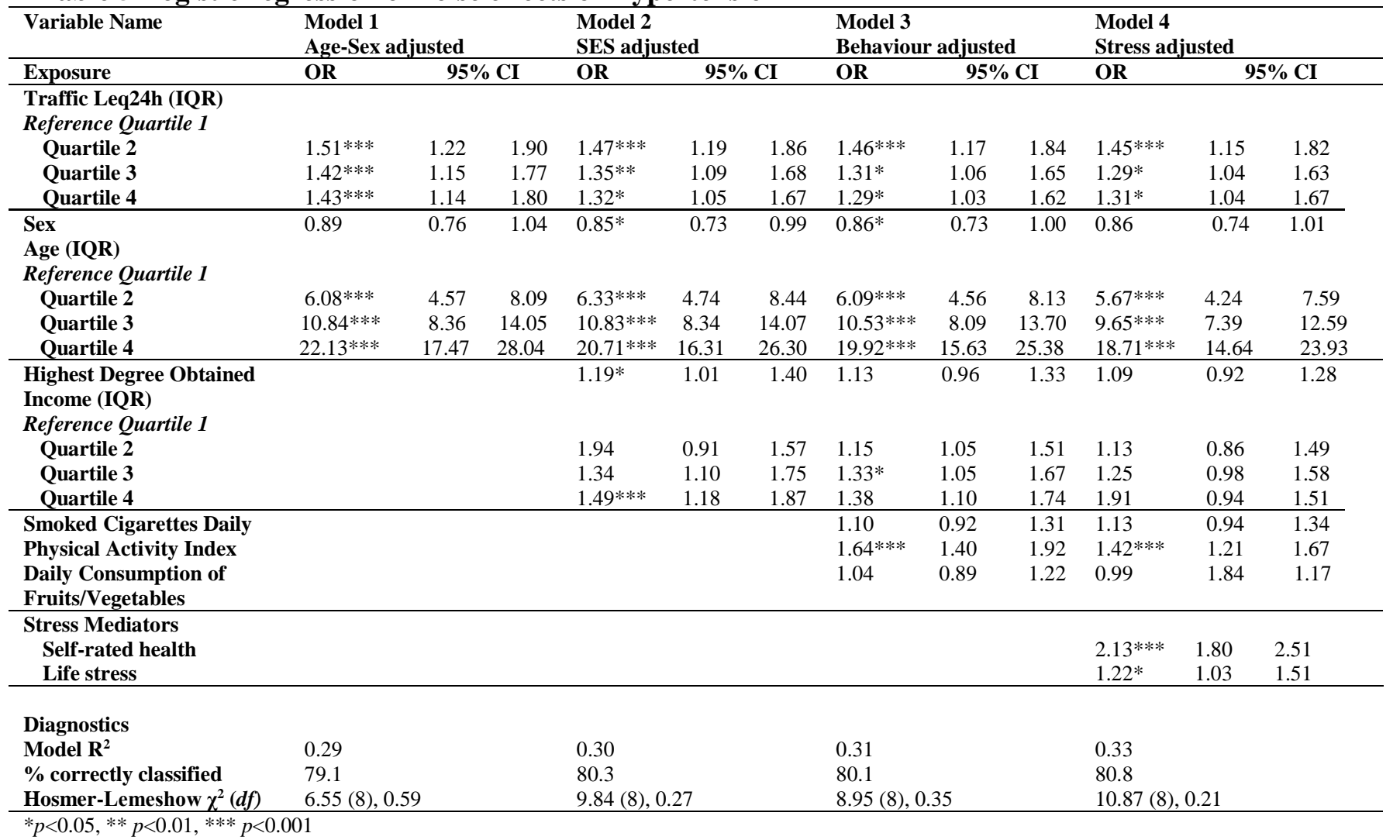


The first logistic regression model assessed noise effects alone on hypertension. It showed that respondents exposed to levels of noise $52 \mathrm{~dB}(\mathrm{~A})$ and higher were more likely to have hypertension. Age, socioeconomic status, behavioural and lifestyle choices, as well as overall wellbeing were significant when assessed with noise effects. Compared to the $1^{\text {st }}$ quartile in reference below $51 \mathrm{~dB}(\mathrm{~A})$ all levels of noise exposure increased the risk of hypertension. While no clear dose response was observed, the odds ratios of elevated noise exposure ranged from 1.42-1.51. When controlling for the influence of socioeconomic status, the effects of noise remained significant. However, the effect of high noise exposure was slightly reduced, suggesting the effect of socioeconomic status is strongest within the highest exposure group. There were some confounding effects by stress mediators.

Table 6 Logistic regression of greenspace effects on hypertension

\begin{tabular}{|c|c|c|c|c|c|c|c|c|c|c|c|c|}
\hline \multirow{3}{*}{$\begin{array}{l}\text { Variable Name } \\
\text { Exposure } \\
\text { PR Less than } 1 \text { Hc 200m }\end{array}$} & \multicolumn{3}{|c|}{$\begin{array}{l}\text { Model } 1 \\
\text { Age-Sex adjusted }\end{array}$} & \multicolumn{3}{|c|}{$\begin{array}{l}\text { Model 2 } \\
\text { SES adjusted }\end{array}$} & \multicolumn{3}{|c|}{$\begin{array}{l}\text { Model } 3 \\
\text { Behaviour adjusted }\end{array}$} & \multicolumn{3}{|c|}{$\begin{array}{l}\text { Model } 4 \\
\text { Stress adjusted }\end{array}$} \\
\hline & \multirow{2}{*}{$\begin{array}{l}\text { OR } \\
1.19\end{array}$} & \multicolumn{2}{|c|}{$95 \% \mathrm{CI}$} & \multirow{2}{*}{$\begin{array}{l}\text { OR } \\
1.18\end{array}$} & \multicolumn{2}{|c|}{$95 \% \mathrm{CI}$} & \multirow{2}{*}{$\begin{array}{l}\mathbf{O R} \\
1.21 *\end{array}$} & \multicolumn{2}{|c|}{$95 \% \mathrm{CI}$} & \multirow{2}{*}{$\begin{array}{l}\mathbf{O R} \\
1.18\end{array}$} & \multicolumn{2}{|c|}{$95 \% \mathrm{CI}$} \\
\hline & & 0.99 & 1.45 & & 0.99 & 1.43 & & 1.00 & 1.46 & & 0.97 & 1.43 \\
\hline $\begin{array}{l}\text { Sex } \\
\text { Age (IOR) }\end{array}$ & 0.90 & 0.77 & 1.04 & $0.85^{*}$ & 0.73 & 1.00 & $0.86^{*}$ & 0.73 & 1.00 & 0.86 & 0.74 & 1.01 \\
\hline \multicolumn{13}{|l|}{$\begin{array}{l}\text { Age (IQR) } \\
\text { Reference Quartile } 1\end{array}$} \\
\hline Quartile 2 & $6.01 * * *$ & 4.52 & 8.00 & $6.25 * * *$ & 4.69 & 8.34 & $6.01 * * *$ & 4.50 & 8.02 & $5.59 * * *$ & 4.18 & 7.48 \\
\hline Quartile 3 & $10.73 * * *$ & 8.28 & 13.90 & $10.73 * *$ & 8.27 & 13.92 & $10.47 * * *$ & 8.05 & 13.63 & $9.58 * * *$ & 7.35 & 12.50 \\
\hline Quartile 4 & $22.22 * * *$ & 17.55 & 28.15 & $20.65^{* *}$ & 16.27 & 26.22 & $19.96^{* * * *}$ & 15.67 & 25.43 & $18.72 * * *$ & 14.64 & 23.92 \\
\hline Highest Degree Obtained & & & & $1.18^{*}$ & 1.01 & 1.39 & 1.12 & 0.95 & 1.32 & $1.08^{*}$ & 0.91 & 1.27 \\
\hline \multicolumn{13}{|l|}{ Income (IQR) } \\
\hline Quartile 2 & & & & 1.24 & 0.95 & 1.63 & 1.87 & 0.91 & 1.56 & 1.17 & 0.89 & 1.54 \\
\hline Ouartile 3 & & & & $1.45^{*}$ & 1.15 & 1.82 & 1.37 & 1.09 & 1.73 & $1.29 *$ & 1.02 & 1.63 \\
\hline Quartile 4 & & & & $1.56^{* * * *}$ & 1.25 & 1.96 & $1.44 *$ & 1.15 & 1.80 & 1.24 & 0.98 & 1.57 \\
\hline Smoked Cigarettes Daily & & & & & & & 1.08 & 0.91 & 1.28 & 1.11 & 0.93 & 1.32 \\
\hline Physical Activity Index & & & & & & & $1.66^{* * * *}$ & 1.42 & 1.94 & $1.44 * * *$ & 1.22 & 1.69 \\
\hline $\begin{array}{l}\text { Daily Consumption of } \\
\text { Fruits/Vegetables }\end{array}$ & & & & & & & 1.04 & 0.89 & 1.23 & 0.99 & 0.84 & 1.17 \\
\hline \multicolumn{13}{|l|}{ Stress Mediators } \\
\hline Self-rated health & & & & & & & & & & $2.13 * * *$ & 1.80 & 2.53 \\
\hline Life stress & & & & & & & & & & $1.22 *$ & 1.00 & 1.48 \\
\hline \multicolumn{13}{|l|}{ Diagnostics } \\
\hline Model $\mathbf{R}^{2}$ & 0.29 & & & 0.30 & & & 0.31 & & & & & \\
\hline$\%$ correctly classified & 79.5 & & & 79.9 & & & 80.2 & & & 80.9 & & \\
\hline Hosmer-Lemeshow $\chi^{2}(d f)$ & $6.03(7)$ & & & $3.33(8)$, & & & $7.64(8)$ & & & $13.99(8)$, & 0.08 & \\
\hline
\end{tabular}


The second logistic regression model assessed the effects of greenspace on hypertension (Table

4). We observed an effect of proximity to greenspace increasing the risk of hypertension by $20 \%$, although this was not significant. Greenspace significance was only observed when controlling for behaviour, suggesting a confounding effect between the two variables. The effect disappeared when controlling for stress suggesting a confounding effect between the two mediators.

When controlling for both greenspace and noise, the effects on hypertension remained comparable to their individual effects (Table 5). There was a very small buffering effect. There was a slight decrease in effects of noise within the model.

Table 7 Logistic regression results of the noise effects on hypertension when controlling for greenspace

\begin{tabular}{|c|c|c|c|c|c|c|c|c|c|c|c|c|}
\hline \multirow{2}{*}{$\begin{array}{l}\text { Variable Name } \\
\text { Exposure }\end{array}$} & \multicolumn{3}{|c|}{$\begin{array}{l}\text { Model } 1 \\
\text { Age-Sex adjusted }\end{array}$} & \multicolumn{3}{|c|}{$\begin{array}{l}\text { Model } 2 \\
\text { SES adjusted }\end{array}$} & \multicolumn{3}{|c|}{$\begin{array}{l}\text { Model } 3 \\
\text { Behaviour adjusted }\end{array}$} & \multicolumn{3}{|c|}{$\begin{array}{l}\text { Model } 4 \\
\text { Stress adjusted }\end{array}$} \\
\hline & \multirow[t]{2}{*}{ OR } & \multicolumn{2}{|c|}{$95 \% \mathrm{CI}$} & \multirow[t]{2}{*}{ OR } & \multicolumn{2}{|c|}{$95 \% \mathrm{CI}$} & \multirow[t]{2}{*}{ OR } & \multicolumn{2}{|c|}{$95 \% \mathrm{CI}$} & \multirow[t]{2}{*}{ OR } & \multicolumn{2}{|c|}{$95 \% \mathrm{CI}$} \\
\hline \multicolumn{9}{|l|}{ Traffic Leq24h (IQR) } & & & & \\
\hline \multicolumn{13}{|l|}{ Reference Quartile 1} \\
\hline Quartile 2 & $1.50 * * *$ & 1.21 & 1.88 & $1.46^{* * *}$ & 1.17 & 1.84 & $1.45^{* *} *$ & 1.17 & 1.82 & $1.44 * *$ & 1.16 & 1.79 \\
\hline Quartile 3 & $1.43 * *$ & 1.16 & 1.77 & $1.35^{* *} *$ & 1.09 & 1.70 & $1.31^{*}$ & 1.07 & 1.65 & $1.30^{*}$ & 1.03 & 1.62 \\
\hline Quartile 4 & $1.43^{* *}$ & 1.14 & 1.80 & $1.32 *$ & 1.05 & 1.67 & $1.29 *$ & 1.03 & 1.62 & $1.31^{*}$ & 1.04 & 1.70 \\
\hline PR Less than $1 \mathrm{Hc} 200 \mathrm{~m}$ & 1.18 & 1.00 & 1.42 & 1.18 & 0.99 & 1.40 & $1.20^{*}$ & 1.01 & 1.43 & 1.18 & 0.98 & 1.40 \\
\hline Sex & 0.89 & 0.76 & 1.03 & $0.85^{*}$ & 0.73 & 0.99 & $0.86^{*}$ & 0.73 & 1.00 & 0.86 & 0.74 & 1.01 \\
\hline \multicolumn{13}{|l|}{ Age (IQR) } \\
\hline \multicolumn{13}{|l|}{ Reference Quartile 1} \\
\hline Quartile 2 & $6.07 * * *$ & 4.56 & 8.08 & $6.31 * * *$ & 4.73 & 8.42 & $6.07 * * *$ & 4.54 & 8.10 & $5.65 * * *$ & 4.22 & 7.56 \\
\hline Quartile 3 & $10.86^{* * * *}$ & 8.38 & 14.08 & $10.85^{* * *} *$ & 8.36 & 14.09 & $10.56^{* * *}$ & 8.10 & 13.75 & $9.67 * * *$ & 7.41 & 12.62 \\
\hline Quartile 4 & $22.24 * * *$ & 17.55 & 28.18 & $20.81 * * *$ & 16.39 & 26.43 & $20.05^{* * *} *$ & 15.73 & 25.55 & $18.82^{* *}$ & 14.71 & 24.06 \\
\hline Highest Degree Obtained & & & & $1.19 *$ & 1.01 & 1.40 & 1.12 & 0.95 & 1.32 & 1.08 & 0.91 & 1.28 \\
\hline \multicolumn{13}{|l|}{ Income (IQR) } \\
\hline \multicolumn{13}{|l|}{ Reference Quartile 1} \\
\hline Quartile 2 & & & & 1.20 & 0.91 & 1.57 & 1.15 & 0.87 & 1.51 & 1.31 & 0.86 & 1.49 \\
\hline Quartile 3 & & & & $1.39 * *$ & 1.10 & 1.75 & $1.33^{* *}$ & 1.05 & 1.68 & 1.25 & 0.99 & 1.58 \\
\hline Quartile 4 & & & & $1.49 * * *$ & 1.18 & 1.87 & 1.38 & 1.10 & 1.74 & 1.19 & 0.94 & 1.51 \\
\hline Smoked Cigarettes Daily & & & & & & & 1.09 & 0.92 & 1.30 & 1.12 & 0.94 & 1.33 \\
\hline Physical Activity Index & & & & & & & $1.65^{* * * *}$ & 1.41 & 1.93 & $2.13^{* * * *}$ & 1.21 & 1.68 \\
\hline \multicolumn{13}{|l|}{ Daily Consumption of } \\
\hline Fruits/Vegetables & & & & & & & 1.04 & 0.88 & 1.22 & 0.99 & 0.84 & 1.17 \\
\hline \multicolumn{13}{|l|}{ Stress Mediators } \\
\hline Self-rated health & & & & & & & & & & $2.13 * * *$ & 1.82 & 2.51 \\
\hline Life stress & & & & & & & & & & $1.22 *$ & 1.00 & 1.48 \\
\hline \multicolumn{13}{|l|}{ Diagnostics } \\
\hline Model $\mathbf{R}^{2}$ & 0.29 & & & 0.30 & & & 0.31 & & & 0.33 & & \\
\hline$\%$ correctly classified & 79.3 & & & 80.3 & & & 80.4 & & & 80.9 & & \\
\hline Hosmer-Lemeshow $\chi^{2}(d f)$ & $5.76(8),($ & & & $6.12(8), c$ & .63 & & $7.07(8),($ & & & $12.47(8)$ & 0.13 & \\
\hline
\end{tabular}

$* p<0.05, * * p<0.01, * * * p<0.001$

The results of the air quality effects on hypertension is presented in (Table 6). When controlling for nitrogen dioxide $\left(\mathrm{NO}_{2}\right)$, there was a small and insignificant effect observed on hypertension. 
When $\mathrm{NO}_{2}$ was tested with exposure to noise and access to greenspace in the same model (Table 7), the effects decreased.

The effects of multiple environmental exposures and the distance to greenspace was assessed in the statistical model presented in Table 7. The effects of noise remained constant throughout all four models. The significance of income disappeared when controlling for stress mediators only in models controlling for noise. This suggests that there is a confounding effect between noise and income and stress.

Table 8 Logistic regression results of the air quality effects on hypertension

\begin{tabular}{|c|c|c|c|c|c|c|c|c|c|c|c|c|}
\hline \multirow{3}{*}{$\begin{array}{l}\text { Variable Name } \\
\text { Exposure } \\
\text { Nitrogen dioxide (ppb) }\end{array}$} & \multicolumn{3}{|c|}{$\begin{array}{l}\text { Model } 1 \\
\text { Age-Sex adjusted }\end{array}$} & \multicolumn{3}{|c|}{$\begin{array}{l}\text { Model } 2 \\
\text { SES adjusted }\end{array}$} & \multicolumn{3}{|c|}{$\begin{array}{l}\text { Model } 3 \\
\text { Behaviour adjusted }\end{array}$} & \multicolumn{3}{|c|}{$\begin{array}{l}\text { Model } 4 \\
\text { Stress adjusted }\end{array}$} \\
\hline & \multirow{2}{*}{$\begin{array}{l}\mathbf{O R} \\
1.02\end{array}$} & \multicolumn{2}{|c|}{$95 \% \mathrm{CI}$} & \multirow{2}{*}{$\begin{array}{l}\mathbf{O R} \\
1.01\end{array}$} & \multicolumn{2}{|c|}{$95 \% \mathrm{CI}$} & \multirow{2}{*}{$\begin{array}{l}\text { OR } \\
1.01\end{array}$} & \multicolumn{2}{|c|}{$95 \% \mathrm{CI}$} & \multirow{2}{*}{$\begin{array}{l}\mathbf{O R} \\
1.01\end{array}$} & \multicolumn{2}{|c|}{$95 \% \mathrm{CI}$} \\
\hline & & 0.99 & 1.04 & & 0.98 & 1.04 & & 0.98 & 1.03 & & 0.98 & 1.04 \\
\hline Sex & 0.89 & 0.77 & 1.04 & $0.85^{*}$ & 0.73 & 0.99 & $0.85^{*}$ & 0.73 & 1.00 & 0.86 & 0.73 & 1.01 \\
\hline \multicolumn{13}{|l|}{ Age (IQR) } \\
\hline \multicolumn{13}{|l|}{ Reference Quartile 1} \\
\hline Quartile 2 & $5.95 * * *$ & 4.47 & 7.92 & $6.20 * * *$ & 4.65 & 8.27 & $5.96^{* * *} *$ & 4.46 & 7.96 & $5.54 * * *$ & 4.14 & 7.42 \\
\hline Quartile 3 & $10.70 * * *$ & 8.25 & 13.88 & $10.70 * * *$ & 8.24 & 13.89 & $10.41 * * *$ & 8.00 & 13.56 & $9.52 * * *$ & 7.29 & 12.42 \\
\hline Quartile 4 & $22.07 * * *$ & 17.43 & 27.96 & $20.50 * * *$ & 16.15 & 26.02 & $19.77 * * *$ & 15.52 & 25.19 & $18.57 * * *$ & 14.53 & 23.75 \\
\hline Highest Degree Obtained & & & & $1.20^{*}$ & 1.01 & 1.40 & 1.13 & 0.95 & 1.33 & 1.08 & 0.92 & 1.28 \\
\hline \multicolumn{13}{|l|}{ Income (IQR) } \\
\hline \multicolumn{13}{|l|}{ Reference Quartile 1} \\
\hline Quartile 2 & & & & 1.27 & 0.97 & 1.67 & 1.22 & 0.93 & 1.60 & 1.20 & 0.91 & 1.59 \\
\hline Quartile 3 & & & & $1.45^{*}$ & 1.15 & 1.82 & 1.38 & 1.09 & 1.74 & $1.30 *$ & 1.02 & 1.64 \\
\hline Quartile 4 & & & & $1.57 * * *$ & 1.25 & 1.97 & $1.45 * * *$ & 1.15 & 1.82 & 1.25 & 0.94 & 1.58 \\
\hline Smoked Cigarettes Daily & & & & & & & 1.09 & 0.92 & 1.30 & 1.12 & 0.94 & 1.33 \\
\hline Physical Activity Index & & & & & & & $1.65^{* * * *}$ & 1.41 & 1.93 & $1.43 * * *$ & 1.21 & 1.68 \\
\hline $\begin{array}{l}\text { Daily Consumption of } \\
\text { Fruits/Vegetables }\end{array}$ & & & & & & & 1.05 & 0.89 & 1.24 & 1.00 & 0.85 & 1.18 \\
\hline \multicolumn{13}{|l|}{ Stress Mediators } \\
\hline Self-rated health & & & & & & & & & & $2.13^{* * *} *$ & 1.82 & 2.51 \\
\hline Life stress & & & & & & & & & & $1.22 *$ & 1.01 & 1.49 \\
\hline \multicolumn{13}{|l|}{ Diagnostics } \\
\hline Model $\mathbf{R}^{2}$ & 0.29 & & & 0.30 & & & 0.31 & & & 0.33 & & \\
\hline$\%$ correctly classified & 79.4 & & & 79.2 & & & 80.0 & & & 80.8 & & \\
\hline Hosmer-Lemeshow $\chi^{2}(d f)$ & $5.11(\mathrm{df})$ & 29 & & $3.32(8)$, & & & $7.79(8), 0$ & .45 & & $6.27(8), 0$ & & \\
\hline
\end{tabular}

Age had a significant effect throughout all models. The education variable was controlled for and had a significant effect along with income, but this was not observed when controlling for behavioural variables. It was observed that cigarette smoking had a small and insignificant effect throughout all models. The physical activity variable was statistically significant throughout each 
logistic regression model. Daily consumption of fruits and vegetables did not have a significant effect throughout all four models.

\begin{tabular}{|c|c|c|c|c|c|c|c|c|c|c|c|c|}
\hline \multirow{2}{*}{$\begin{array}{l}\text { Variable Name } \\
\text { Exposure }\end{array}$} & \multicolumn{3}{|c|}{$\begin{array}{l}\text { Model } 1 \\
\text { Age-Sex adjusted }\end{array}$} & \multicolumn{3}{|c|}{$\begin{array}{l}\text { Model } 2 \\
\text { SES adjusted } \\
\end{array}$} & \multicolumn{3}{|c|}{$\begin{array}{l}\text { Model } 3 \\
\text { Behaviour adjusted }\end{array}$} & \multicolumn{3}{|c|}{$\begin{array}{l}\text { Model } 4 \\
\text { Stress adjusted }\end{array}$} \\
\hline & \multirow[t]{2}{*}{ OR } & \multicolumn{2}{|c|}{$95 \% \mathrm{CI}$} & \multirow[t]{3}{*}{ OR } & \multicolumn{2}{|c|}{$95 \% \mathrm{CI}$} & \multirow[t]{2}{*}{ OR } & \multicolumn{2}{|c|}{$95 \% \mathrm{CI}$} & \multirow[t]{3}{*}{ OR } & \multicolumn{2}{|c|}{$95 \% \mathrm{CI}$} \\
\hline \multicolumn{9}{|l|}{ Traffic Leq24h (IQR) } & & & & \\
\hline & & & & & & & & & & & & \\
\hline Quartile 2 & $1.60 * * *$ & 1.27 & 1.97 & $1.56 * * *$ & 1.23 & 1.93 & $1.55^{* * * *}$ & 1.21 & 1.95 & $1.54 * * *$ & 1.21 & 1.95 \\
\hline Quartile 3 & $1.47 * *$ & 1.15 & 1.86 & $1.39 * *$ & 1.09 & 1.75 & $1.37 * *$ & 1.08 & 1.73 & $1.36^{* *}$ & 1.07 & 1.72 \\
\hline Quartile 4 & $1.41 * *$ & 1.09 & 1.77 & $1.30 *$ & 1.01 & 1.65 & $1.28 *$ & 0.99 & 1.63 & $1.29 *$ & 1.00 & 1.63 \\
\hline Nitrogen dioxide (ppb) & 0.97 & 0.90 & 1.04 & 0.96 & 0.90 & 1.03 & 0.95 & 0.89 & 1.02 & 0.95 & 0.88 & 1.02 \\
\hline PR Less than $1 \mathrm{Hc} 200 \mathrm{~m}$ & 1.17 & 0.98 & 1.40 & 1.17 & 0.96 & 1.40 & 1.19 & 0.99 & 1.42 & 1.18 & 0.97 & 1.42 \\
\hline \multicolumn{13}{|l|}{$\begin{array}{l}\text { Interaction of traffic noise } \\
\text { and nitrogen dioxide } \\
\text { Zscore } \\
\text { Reference Quartile 1 }\end{array}$} \\
\hline Quartile 2 & 1.24 & 0.91 & 1.65 & 1.26 & 0.93 & 1.68 & 1.29 & 0.96 & 1.72 & 1.30 & 0.97 & 1.75 \\
\hline Quartile 3 & 1.09 & 0.84 & 1.42 & 1.10 & 0.85 & 1.45 & 1.13 & 0.88 & 1.49 & 1.16 & 0.90 & 1.52 \\
\hline Quartile 4 & 1.17 & 0.90 & 1.52 & 1.20 & 0.92 & 1.55 & 1.24 & 0.96 & 1.62 & $1.28 *$ & 0.98 & 1.67 \\
\hline Sex & 0.89 & 0.76 & 1.03 & $0.85^{*}$ & 0.73 & 0.99 & $0.85^{*}$ & 0.73 & 1.00 & 0.86 & 0.73 & 1.01 \\
\hline \multicolumn{13}{|l|}{ Age (IQR) } \\
\hline \multicolumn{13}{|l|}{ Reference Quartile 1} \\
\hline Quartile 2 & $5.97 * * *$ & 4.48 & 7.95 & $6.21 * * *$ & 4.65 & 8.28 & $5.97 * * *$ & 4.67 & 7.98 & $5.55^{* * * *}$ & 4.14 & 7.43 \\
\hline Quartile 3 & $10.81 * * *$ & 8.33 & 14.03 & $10.80 * * *$ & 8.31 & 14.03 & $10.50 * * *$ & 8.06 & 13.68 & $7.34 * * *$ & 7.34 & 12.52 \\
\hline Quartile 4 & $22.16 * * *$ & 17.48 & 28.08 & $20.68 * * *$ & 16.28 & 26.28 & $19.94 * * *$ & 15.64 & 25.42 & $18.73 * * *$ & 14.64 & 23.87 \\
\hline \multirow{2}{*}{\multicolumn{13}{|c|}{$\begin{array}{l}\text { Income (IQR) } \\
\text { Reference Quartile } 1\end{array}$}} \\
\hline & & & & & & & & & & & & \\
\hline Quartile 2 & & & & 1.24 & 0.94 & 1.62 & 1.19 & 0.90 & 1.56 & 1.17 & 0.89 & 1.55 \\
\hline Quartile 3 & & & & $1.41 *$ & 1.12 & 1.78 & $1.35^{* *}$ & 1.06 & 1.70 & $1.27 *$ & 1.00 & 1.61 \\
\hline Quartile 4 & & & & $1.52 * * *$ & 1.21 & 1.91 & $1.41 * *$ & 1.12 & 1.77 & 1.22 & 0.96 & 1.55 \\
\hline Smoked Cigarettes Daily & & & & & & & 1.10 & 0.92 & 1.30 & 1.21 & 0.94 & 1.34 \\
\hline Physical Activity Index & & & & & & & $1.66^{* * * *}$ & 1.41 & 1.94 & $1.44 * * *$ & 1.22 & 1.69 \\
\hline $\begin{array}{l}\text { Daily Consumption of } \\
\text { Fruits/Vegetables }\end{array}$ & & & & & & & 1.05 & 0.89 & 1.23 & 1.00 & 0.87 & 1.18 \\
\hline \multicolumn{13}{|l|}{ Stress Mediators } \\
\hline Self-rated health & & & & & & & & & & $2.12 * * *$ & 1.80 & 2.53 \\
\hline Life stress & & & & & & & & & & $1.24 *$ & 1.01 & 1.49 \\
\hline \multicolumn{13}{|l|}{ Diagnostics } \\
\hline Model $\mathbf{R}^{2}$ & 0.30 & & & 0.30 & & & 0.31 & & & 0.33 & & \\
\hline$\%$ correctly classified & 79.8 & & & 80.3 & & & 80.3 & & & 81.3 & & \\
\hline Hosmer-Lemeshow $\chi^{2}(d f)$ & $5.23(8),($ & & & $6.20(8),($ & & & $12.99(8)$ & 0.11 & & $8.92(8), 0$ & .35 & \\
\hline
\end{tabular}

$* p<0.05, * * p<0.01, * * * p<0.001$ 


\subsection{Discussion}

This study investigated the effects of multiple environmental exposures on hypertension and found that the effect of noise pollution was individually significant. It was also evident that noise levels exceeding $55 \mathrm{~dB}$ was higher around major roads and highways (figure 4). It was observed that $75.37 \%$ of respondents stated they do not have one hectare of greenspace within a 200 metre distance from their residence (Table 1). The mean average of 24-hour traffic noise respondents were exposed to was $56.99 \mathrm{dBA}$. Table 5 showed significant odds ratios of the individual exposure effects of noise on hypertension above the reference category. Babisch et al. (2014) find that acute exposure to noise causes physiological effects on both the autonomic nervous and endocrine system. The body perceives noise to be a stressful event where it activates the sympathetic nervous system (Hammer et al., 2014). As blood pressure rises due to noise levels, so does the heartrate which causes an increase of cortisol secretion (Hammer et al., 2014). They also find that exposure to higher than recommended levels of noise can be a risk factor for hypertension (Babisch et al., 2014). Hammer et al. (2014) suggests that noise-disturbed sleep results in increased levels of stress related hormones.

Noise pollution was also significant when modeled with air pollution and greenspace. Greenspace effects on hypertension was significant when behavioural variables were controlled for in model 3. The World Health Organization suggests that individuals will likely use greenspace for physical activity if the area is large enough (2011). In table 3, it was observed that accessibility to greenspace only had a significant statistical relationship with the physical activity index used in the model. Gildof et al. (2007) also find that residents who have access to greenspace are more likely to use it for physical activity and view it as a positive soundscape. 
Hansmann et al. (2007) find that respondents in their study used greenspace for recreational purposes and an outlet to alleviate stress.

Air quality was not significant except for the highest exposure quartile when multiple exposures were modeled. $\mathrm{NO}_{2}$ was unevenly distributed throughout census tracts where air quality was noticeably lower in eastern Toronto (figure 5). $\mathrm{NO}_{2}$ is not typically considered a direct cardiovascular risk factor. The study conducted by Forester et al. (2014) observe an effect on chronic exposure to $\mathrm{NO}_{2}$ and hypertension. Forester et al. (2014) suggest the lack of acute effects of air pollution could be temporally related. Air pollution can affect the body through multiple physiological pathways which may not be acutely noticeable (Tétreault et al., 2013). Tétreault et al. (2013) state that air and noise pollution induce stress outcomes through different pathways which may explain why noise effects are significant while air effects are not. Brook \& Kousha (2015) suggest that low concentrations of air pollution is able to display 'clinically meaningful' results. Newby et al. (2015) also find that many studies assessing air pollution and cardiovascular disease can positively be associated to acute exposure to health effects.

Very few studies assess the effects of multiple environmental exposures on cardiovascular health. The studies that have assessed the effects of both environmental exposures find results to be conflicting (Oiamo, 2014). Tétreault et al. (2013) suggest that the effect of exposure to trafficrelated air pollution and noise should continue to be analyzed because of the unclear relationship between the two.

Among the total female respondents, 57.55\% reported hypertension. Although hypertension affects both sexes, evidence shows that the prevalence of hypertension is greater in older women than men (August, 2013; Lima et al., 2012; Pimenta, 2012). Cardiovascular risks for women are higher for those in lower socioeconomic groups (Mobley et al., 2006). Women who reside in 
lower income communities are more likely to have little access to healthy dietary choices and lack in the promotion of physical activity (Mobley et al., 2006). Inequalities amongst the female population in lower socioeconomic status communities can be attributed to the triple jeopardy approach where health status is based on social hierarchies.

The physical features of a neighbourhood can influence health status where mixed-use communities and access to greenspace can promote healthier behavioural habits and physical activity (Mobley et al., 2006). Lima et al. (2012) contribute higher prevalence of hypertension to postmenopausal women, likely influenced by varying estrogen and progesterone levels, and sympathetic activation. August (2013) suggests higher prevalence in postmenopausal women and the use of oral contraceptives may also play an important role in higher levels of blood pressure (Pimenta, 2012). Among the respondents, the 56-65 age group had 22.15\% reported hypertension. The 66+ category had 57.09\% reported hypertension. The stiffening of blood vessels because of ageing is one of the reasons why hypertension is more prevalent in the older generation (World Health Organization, 2013). As predicted, age had a strong effect on hypertension in all logistic regression models.

The Unequal City 2015 concludes that residents of lower socioeconomic status have worse health than those of higher status, and health inequalities continue to persist in Toronto (Toronto Public Health, 2015). In the covariate matrix (table 3), it is also important to note that the socioeconomic variables displayed a statistically significant relationship with the stress and demographics covariates in addition to the 24-hour traffic noise variable (Table 3). Among those who reported completing high school or less, $47.54 \%$ reported hypertension. Respondents who reported to making less than 40,000\$, $26.48 \%$ reported hypertension. Working conditions impact stress levels depending on the type of work an individual is performing (World Health 
Organization, 2013). The work environment may consequently lead to greater exposure to environmental stressors (World Health Organization, 2013). Subramanian et al. (2010) report that higher education is linked to healthier well-being. Subramanian et al. (2010) suggest the lack of education can negatively impact the health status of individuals. Life stress can be addressed as both a psychological factor, linked to socioeconomic status, and a physiological factor, linking health concerns to illness (Ames et al., 2001). Socioeconomic status is the most influential driver on health status (Toronto Public Health, 2015). Stress from a wide array of social and economic driven factors can weaken the immune system and can generate unhealthy behavioural patterns like unhealthy eating and lack of physical activity (Toronto Public Health, 2015). Population groups of higher socioeconomic status often have better access to healthcare services and better resources to cope with health deterrents (Toronto Public Health, 2015).

When adjusting for behaviour and lifestyle variables, greenspace was significant. The reasoning behind this phenomenon can be explained through the promotion of physical activity through the accessibility to greenspace. Taylor and Hochuli (2015) suggest greenspace is a natural catalyst to promote physical activity and positive health and wellbeing. Evidence in the current study showed the significant effect physical activity had on individual health and wellbeing through the use of greenspace. Lachowycz and Jones also support the argument that greenspace influences more physical activity. In their study they state that respondents who live closer to greenspaces use it more frequently than those who do not (Lachowycz \& Jones, 2014). Barton et al. (2009) also concur with the findings of Lachowycz \& Jones, while adding that greenspace promotes a healthy social capital within communities. Neighbourhood greenspace and adequate accessibility to greenspace promotes physical activity and an active lifestyle (World Health 
Organization, 2016b). Greenspace would encourage individuals living in urban areas to move away from the sedentary lifestyle (World Health Organization, 2016b).

Life stress findings indicate that life stressors indicate health disparities and inequalities. The stress variables resulted in significant values and can be explained by the use of greenspace as therapeutic landscapes. Therapeutic landscapes are viewed as a location that is built on cultural and social constructs (Day, 2007). Therapeutic landscapes are associated with mental wellbeing and healing (Day, 2007; Gesler, 1992). Hansen et al. (2017) supply evidence showing greenspace providing therapeutic effects through forest bathing. Evidence shows that forest bathing, spending time immersing oneself in nature, is beneficial for reducing blood pressure and improving cardiovascular health (Hansen et al., 2017).

\subsubsection{Limitations}

A major limitation of this analysis is that it is cross-sectional in design. As a result, there are confined restraints of studying a population within one specific time frame. Some of the cardiovascular stressors addressed within the study were not significant. Findings can inaccurately suggest that stressors like smoking is not a definitive risk factor to cardiovascular health. The results suggest that the cross-sectional designed study does not have temporal information pertaining to the effects of smoking on cardiovascular health. The cross-sectional study limits the understanding of the temporal presence of other risk factors pertaining to cardiovascular disease. A longitudinal study would further validate the results of this study, as it would provide more insight on the implications of spatial adjustments of respondents. The final limitation of the study was the use of the $\mathrm{NO}_{2}$ dataset. $\mathrm{NO}_{2}$ was used as an indicator of overall exposure which could have hindered the strength of the air quality results. 


\subsubsection{Conclusion}

Air and noise pollution are environmental stressors that typically exceed acceptable levels in an urban setting. This study shows that both environmental stressors and the lack of available greenspace hindered the health of respondents living in Toronto. Unfortunately, there are limited studies that have assessed noise and air pollution simultaneously (Babisch et al., 2014). Limited studies suggest the need for further research on the cumulative effects of both environmental stressors (Babisch et al., 2014; Oiamo et al., 2015; Stansfeld, 2015). The study found that respondents who live within a walkable distance to greenspace utilized it for physical activity. This coincides with other studies which stress the importance of access to greenspace in neighbourhoods. Accessible greenspace promotes a healthier lifestyle and enhances both psychological and physiological health. 


\section{Conclusion}

\subsection{Outcome of Thesis Objectives}

Objective 1: To critically assess the individual exposure effects of environmental stressors on hypertension by controlling for physical, behavioural and socioeconomic stressors

Objective one addressed the implications of the environmental stressors that lead to hypertension and life-threatening cardiovascular health effects. This was accomplished by controlling for physical, behavioural and socioeconomic covariates to determine which, if not all, environmental stressors had significant effects on hypertension. This was achieved by performing logistic regression models individually controlling for air pollution, noise pollution, and greenspace, while controlling for demographic, socioeconomic, behavioural, and stress covariates. The results indicated that noise levels exceeding the recommended limit had a significant and shortterm effect on respondents who reported hypertension. Noise levels exceeded recommended levels of $55 \mathrm{~dB}$ throughout the majority of the city (Figure 4). Air pollution did not show significant results when analyzed individually. Greenspace showed significant results when behavioural covariates were controlled for.

Objective 2: To evaluate the effects of multiple environmental exposures attributed to hypertension by controlling for physical, behavioural and socioeconomic stressors

Objective two attempted to address the implications of the cumulative effects of multiple exposures on hypertension. Noise and air quality levels exceeding the recommended limit are often associated with vehicles (Babisch et al., 2014; Fuks et al., 2017). This objective was accomplished by controlling for all environmental exposures simultaneously and controlling for the interacting effects of traffic noise and $\mathrm{NO}_{2}$ (Table 7). The results of the objective showed significant interacting effects of both noise and air quality only when noise levels exceeded 64+ 
decibel levels. Compared to objective one, objective two stresses the importance for more research on the effects of multiple exposures. Although the interaction analysis conducted in this study had shown an effect of both stressors, it was difficult to isolate the cumulative effects of total exposure from the one model. This means that there is still a need for more research addressing noise and air pollution cumulatively.

Objective 3: To assess the role of greenspace to mitigate environmental stress attributed to excessive noise and air pollution

Objective three demonstrated the need to address environmental stressors in Toronto as policybased health matter. Air quality, noise pollution, and accessibility to greenspace should be addressed as a public health concern since it is unevenly distributed in urban areas (Brook et al., 2010). Accessibility to greenspace is beneficial for cardiovascular health and wellbeing (World Health Organization, 2016b). It was shown in the study that many respondents in Toronto do not have adequate access to greenspace. Greenspace within Toronto was measured as an individual exposure variable which resulted in significant effects when controlling for behavioural variables. Significant results were shown when noise pollution was measured while controlling for greenspace and adjusted for behavioural variables. Significant results when behavioural variables were controlled for suggested the need for more greenspace to encourage physical activity and stress reduction.

\subsection{Conclusion and Policy Implementation}

The World Health Organization recommends that ambient noise levels should not exceed a daily average of $55 \mathrm{~dB}$ and a nightly average of $45 \mathrm{~dB}$ (World Health Organization, 1999). Currently, the city of Toronto has a bylaw (Chapter 591) that addresses noise. However, it is outdated and briefly discusses controlling for traffic noise. Implementing newer policy enforcing the 
regulation traffic noise recommendations should be considered by policy makers. Although air pollution has decreased since the mid 1900s, reduction has been discarded due to rapid population and economic growth and intensified vehicular traffic (Ewing et al., 2014). Like noise, the reduction of air pollution should be heavily centred around the reduction of traffic volume. In addition to reducing traffic volume, reducing vehicle dependency should be another goal to reduce air pollution. Reducing health inequalities can be tackled in health services through the integration of environmental exposures and the determinants of health into practice (Toronto Public Health, 2015). Persuading Toronto residents to take alternative modes of transportation would force the city to improve public transit infrastructure. Greener modes of transportation including biking and walking should be encouraged as an alternative mode of transportation. Toronto is one of the largest cities Canada with an ageing demographic. The city of Toronto does not have adequate accessible greenspace to improve the health of Torontonians. The results of the Unequal City 2015 report specifies the need for policy planners and healthcare stakeholders to direct their attention to reducing the health inequalities experienced by lower income groups (Toronto Public Health, 2015). The report concludes that the health of population groups from lower income status has not improved over a 10-year time frame which reiterates the need for policy planners and healthcare workers to focus on the reduction of health inequalities (Toronto Public Health, 2015). The reduction of health inequalities requires interdisciplinary action since health is strongly influenced by factors outside of the doctor's office (Toronto Public Health, 2015). The city of Toronto should investigate community garden projects, as community gardens can help promote social cohesion and community involvement and healthier neighbourhoods (Wakefield et al., 2007). The simple decision to plant more trees is more cost-effective solution if incorporating more greenspace is not plausible. 
The main finding of the study was exposure to environmental stressors present serious cardiovascular health concerns by the effect of noise pollution on hypertension. Prevalence of cardiovascular disease can be reduced through greenspace. Greenspace buffers air and noise pollution and promotes physical activity (Taylor and Hochuli, 2015). Greenspace works as a therapeutic space (Day, 2007; Gesler, 1992). A similar study conducted in Bulgaria address the health effects of traffic noise and greenspace. Dzhambov et al. (2018) assess the health effects of road traffic noise and mental health. Although the health endpoints differ, the outcome is similar to this study. Dzhambov et al. (2018) find that greenspace deprived areas were worse for the mental health of their respondents. They propose urban greening which is recommended by experts (Dzhambov et al., 2018). Gildlöf-Gunnarsson and Öhrström (2007) assess the effects of noise and availability of neighbourhood greenspace. They conclude that better accessibility to greenspace is linked to a greater number of residents reporting to use the greenspace for physical activity and to destress (Gildlöf-Gunnarsson and Öhrström, 2007). Their study recommends incorporating quiet areas in the city which is supported by the European Parliament and of the Council (CEC, 2002). Gildlöf-Gunnarsson et al. (2012) assess the before and after effects of implementing the "quiet-side" concept in the centre districts of Gothenburg, Sweden. They find that the construction of a "noise blocking" building improves the soundscape, where noise levels significantly decreased by 8-14 dB (Gildlöf-Gunnarsson et al., 2012). They conclude that the incorporation of a quiet side helps reduce sleep disturbance which is known to affect cardiovascular health (Gildlöf-Gunnarsson et al., 2012). Yli-Pelkonen et al. (2017) assess the effects of trees in urban parks on air quality in Baltimore, Maryland. They find that greenspace lowers the level of air pollutants but find $\mathrm{NO}_{2}$ contradicts their hypothesis that all forms of air pollution will be reduced (Yli-Pelkonen et al., 2017). Their recommendations suggest reducing 
of traffic emissions (Yli-Pelkonen et al., 2017). Proposed solutions to reducing noise and air pollution and incorporating greenspace are shown in several studies to be economically and socially feasible. The city of Toronto is now tasked with incorporating likeminded solutions to reduce the effects of both environmental stressors. In November of 2017, the city of Toronto launched the King Street Pilot project which aims to redirect traffic flow along the third busiest transit corridor in the city. The primary goal is to reduce traffic density but should consider public health research to address health requirements resulting from a dense urban environment. 


\section{Appendices}

\section{APPENDIX A: Project proposal application to access the Research Data Centre (RDC) Title:}

\section{A multilevel analysis of cardiovascular health risks of exposure to environmental stressors at the individual and neighbourhood levels in Toronto, Canada}

\section{Rationale and Objectives}

City dwellers generally experience better health compared to the rural population, but there are notable health inequities within both rural and urban populations, in particular along the income gradient in Canada (DesMeules and Pong, 2006; Pong et al., 2009; Canadian Institute for Health Information, 2015). In addition to income and socioeconomic status more generally, a number of environmental determinants of health can be observed among urban residents. Environmental influences on urban health include characteristics of the built environment and environmental quality. Therefore, when assessing current public health concerns, urbanization and environmental stress can be considered major contributors to human health risks. For the purpose of the proposed research, environmental stress refers to psychological and physiological responses to external stimuli arising from physical and social environments. The particular social and physical environment within which a person is situated can give rise to environmental stressors that have harmful effects on health.

Cardiovascular diseases (CD) are of particular relevance and interest when considering environmental stress, because stressors in both the physical and social environment can present as risk factors. The mechanism that can cause psychological stress to manifest as cardiovascular disease (CD) is well established (Dedovic et al., 2009). Previous research shows that physical environmental stressors that can increase risks for CD include air pollution and noise (Babisch, 2002; Brook et al., 2004). Additionally, the availability of green space presents an important complimentary feature of the built environment to consider because it appears to influence cardiovascular health on its own, but furthermore has a buffering effect on air quality and noise and can therefore have an indirect impact on CD (Richardson et al., 2013). However, a notable gap in previous research concerns how social stressors at the neighbourhood level can moderate the influence of air pollution, noise and available greenspace on CD.

The main objective of the study is to understand how neighbourhood level social stressors influence the relationship between individual environmental risk factors and cardiovascular disease. The following questions will guide the study:

1. Do noise, air pollution, and green space have a direct influence on environmental stress as measured by cardiovascular disease?

2. Do noise, air pollution, and green space interact to influence environmental stress as measured by cardiovascular disease?

3. Are main effects or interaction effects of noise, air pollution and greenspace on cardiovascular disease modified by neighbourhood level social stressors?

The World Health Organization (WHO) has determined that $23 \%$ of all deaths at a global level are caused by environmental stressors. The urban environment can contribute to both psychosocial and biological stress that can lead to higher prevalence rates of CD. The objective 
of the study is to provide theoretical and practical insight on the health risks of environmental stressors from a sociocultural perspective.

Lower income neighbourhoods experience a higher prevalence of $\mathrm{CD}$ that can be attributed to social inequality barriers. Environmental stress is a contributor to many health problems, some of which can be contributed to the inability of individuals being able to maintain a healthy lifestyle. These neighbourhoods are more exposed to cardiovascular reactivity (CVR) related stress where "factors like hostility, depression, social isolation, and low socioeconomic status contribute to CVD", which has been suggested that children with lower socioeconomic status experience social and physical factors that can affect their health once they reach adulthood (Williams et al., 2008; Franco et al., 2017).

Neighbourhoods of lower socioeconomic status are also associated with poorer noise and air quality and higher exposure levels to environmental stressors (Black et al., 2012). Traffic-related noise and particulate matter have also been associated with increased blood pressure (Stansfeld, 2015; Hollingworth et al., 2016). Morello-Frosch et al. (2007) suggest that an area that has lower socioeconomic status is the result of poor planning because they are typically situated around urban areas that are heavily polluted because of industrialized patterns. These neighbourhoods have a higher prevalence rates of $\mathrm{CD}$ and lack environmental justice while being subjected to social stressors like crime, poverty, poor social cohesion, and poor availability of health care services (Agyemang et al., 2007; Morello-Frosch et al., 2007; Euteneuer et al., 2014). Black et al. (2012) suggest that the congruence of social and physical environmental stressors is of particular concern within the aging population as many retire in suburban neighbourhoods where healthcare might not be as accessible. Taken together, previous research provides strong evidence for a theoretical framework that Jerrett et al. (2001) refer to as 'the triple jeopardy' of environmental justice. This framework's main proposition is that individuals who reside in neighbourhoods where social conditions present health risks are often also exposed to physical environmental stressors, and furthermore, experience challenges in navigating the health care system or other institutional resources that could potentially reduce the impact of social and physical environmental stressors.

There are several justifications for conducting research on this issue. Early risk assessments are important for determining potential negative health outcomes from environmental stressors that have been influenced by neighbourhood characteristics (Sexton 2012; Maroko et al., 2014). Women are more likely to seek treatment than men because of a higher level of awareness about their health and wellbeing, which suggests that education and awareness is a solution to reduce the prevalence of CD among vulnerable groups (Bluhm \& Eriksson, 2011). Outcomes of the proposed research may add to a body of evidence on the most effective means of knowledge translation and public awareness concerning vulnerability to physical environmental stressors. Additionally, since mental health concerns are related to geographic location, results of our proposed study may support the implementation of high quality green space to lessen the prevalence of CD and support positive community interaction (Agyemang et al., 2007).

Due to the ageing population and increasing socioeconomic inequities, cardiovascular health remains at the forefront for health concerns. Research shows that ambient exposures to pollutants, geographic location, and psychosocial inequalities are key contributors to the high prevalence rates, which suggests that future work to reduce the number of environmental exposures in these areas will likely lessen the prevalence of CD and its function as a barrier to a 
healthy quality of life for residents in some neighbourhoods. The novel contribution of the research proposed here is a to utilize multilevel modelling to understand how environmental exposures at the individual and neighbourhood levels interact to create cardiovascular health risks. Furthermore, while previous research has focused predominately on single environmental exposures, the objective and rationale of the current study is to focus on multiple physical and social stressors that can impact cardiovascular health.

\section{Proposed Data Analysis and Software Requirements}

The study will utilize individual and neighbourhood level data for two statistical modelling approaches to answer the study questions. Logistic regression allows for the analysis of a binary outcome variable of interest with both continuous and categorical predictor variables. This modelling approach will be used to address questions (1) and (2). Multilevel modelling is a statistical approach that can be used to measure clustered or grouped data using a hierarchical structure (Buxton, 2008). The multilevel modelling approach has been chosen as a suitable option for this study to understand how social stressors at the neighbourhood level can affect the influence of physical environmental stressors experienced by individuals. The data analysis will investigate the potential influence of environmental stressors in the city of Toronto and its neighbourhoods. The city of Toronto has been determined as the case study location because of the cultural diversity and land use characteristics found in different neighbourhoods, as well as the availability of highly resolved data on exposure to environmental noise and air pollution.

Data from the Canadian Community Health Survey will provide individual level control variables and the outcome measure of $\mathrm{CD}$ for the modelling. Furthermore, data at postal code level for estimated exposures to noise, air pollution and available greenspace is available from previous research. This will provide indicators for individual physical environmental stressors. Data from Wellbeing Toronto (hosted by the City of Toronto) at the neighbourhood level will provide relevant information on social environmental stressors, such as crime rates, health care facilities, socioeconomic variables and social capital.

Data taken from all sources will be analyzed in a statistical software package available at the RDC (SPSS/SAS/STATA) after CCHS has been joined to postal code estimates of noise, air pollution and greenspace availability using a geographic information system (GIS; ArcGIS 10.4.1). The statistical software will be used to calculate descriptive statistics with appropriate aggregation for protection of privacy, as well as fitting the logistic regression and multilevel binary logistic regression models. The GIS will also facilitate aggregate visualization of descriptive data.

\section{Data Requirements}

The access to confidential data as opposed to the open source databases is necessary for this study because it is essential that exposures to physical environmental stressors is classified at the lowest geographic level possible, i.e., postal codes. Furthermore, the proposed approach to utilize multilevel modelling requires a hierarchical representation of data nested within neighbourhoods of a sufficient sample size, which cannot be achieved with aggregate data.

The survey files that will be used are the three most recent annual components of the Canadian Community Health Survey (CCHS; 2015, CCHS 2013/2014) which collects data on prevention and detection of disease, disease and health conditions, and health care services. These 
measurements are beneficial for determining health risks of environmental exposures by providing the outcome measure of interest as well as variables to control for potential confounding. The number of datasets being used will not exceed the amount of a typical RDC proposal and will not be merged, pooled, or linked with other Statistics Canada datasets.

Among respondents above the age of 18 only, the variables that will be used have been classified into five categories and are as follows: behavioural, socioeconomics, demographics, cardiovascular health, and healthcare. These variable categories have been determined based on their potential influence on the relationship between environmental stressors and cardiovascular health. The analysis will only utilize data from respondents within the city of Toronto where the sample size is sufficient for the proposed multilevel model.

Geography plays an important role in the data analysis as levels of exposure to physical environmental stressors vary considerably across urban areas such as Toronto. Furthermore, social stressors are commonly observed as distinct between various neighbourhoods of large cities.

\section{Expected project start and end dates}

\begin{tabular}{|l|c|c|}
\hline Activity & Start Date & End Date \\
\hline Prepare geospatial data (noise, air pollution, greenspace) & 15-May-17 & 30-Jun-17 \\
\hline RDC data preparation and exposure classification & $01-\mathrm{Jul}-17$ & 30-Aug-17 \\
\hline RDC data analysis and interpretation & & \\
\hline Report writing and secondary RDC analysis & 01-Sep-17 & 01-Nov-17 \\
\hline Potential follow-up RDC analyses & 02-Nov-17 & 29-Feb-18 \\
\hline
\end{tabular}

\section{Expected Products}

The intended outcome of the project is for a graduate level manuscript thesis for Ryerson University's Environmental Applied Science and Management program that will also be submitted for publication in a peer-reviewed journal.

\section{References}

Agyemang, C., van Hooijdonk, C., Wendel-Vos, W., Ujcic-Voortman, J. K., Lindeman, E., Stronks, K., \& Droomers, M. (2007). Ethnic differences in the effect of environmental stressors on blood pressure and hypertension in the Netherlands. BMC Public Health, 7, 118. https://doi.org/10.1186/1471-2458-7-118.

Babisch, W. (2000). Traffic noise and cardiovascular disease: epidemiological review and synthesis. Noise and health, 2(8), 9. 
Black, D., O’Loughlin, K., Kendig, H., \& Wilson, L. (2012). Cities, environmental stressors, ageing and chronic disease. Australasian Journal on Ageing, 31(3), 147-151.

https://doi.org/10.1111/j.1741-6612.2011.00552.x

Bluhm, G., \& Eriksson, C. (2011). Cardiovascular effects of environmental noise: research in Sweden. Noise Health, 13(52), 212-216. https://doi.org/10.4103/1463-1741.80152.

Brook, R. D., Franklin, B., Cascio, W., Hong, Y., Howard, G., Lipsett, M., ... \& Tager, I. (2004). Air pollution and cardiovascular disease. Circulation, 109(21), 2655-2671.

Buxton, R. (2008). Statistics: Multilevel modelling. Writing, (2000), 1-7.

Canadian Institute for Health Information. Trends in Income-Related Health Inequalities in Canada: Summary Report. Ottawa, ON: CIHI; 2015.

Dedovic, K., Duchesne, A., Andrews, J., Engert, V., \& Pruessner, J. C. (2009). The brain and the stress axis: the neural correlates of cortisol regulation in response to stress. Neuroimage, 47(3), 864-871.

DesMeules, M., Pong, R. W., Laurentian University of Sudbury. Northern Health Research, Public Health Agency of Canada, Canadian Population Health Initiative, \& Canadian Institute for Health Information. (2006). How healthy are rural Canadians?: An assessment of their health status and health determinants Canadian Institute for Health Information.

Euteneuer, F., Mills, P. J., Pung, M. A., Rief, W., \& Dimsdale, J. E. (2014). Neighborhood problems and nocturnal blood pressure dipping. Health Psychology: Official Journal of the Division of Health Psychology, American Psychological Association, 33(11), 1366-72. https://doi.org/10.1037/hea0000004

Ewing, R., Schmid, T., Killingsworth, R., Zlot, A., \& Raudenbush, S. (2003). Relationship between urban sprawl and physical activity, obesity, and morbidity. Urban Ecology: An International Perspective on the Interaction Between Humans and Nature, 18(1), 567-582. https://doi.org/10.1007/978-0-387-73412-5_37

Franco, S., Duarte, C. S., Sandel, M. T., Rosalind, J., Suglia, S. F., Duarte, C. S., ... Wright, R. J. (2017). Social and environmental Stressors in the home and childhood asthma. 64(7), 636642.

Maroko, A. R., Weiss Riley, R., Reed, M., \& Malcolm, M. (2014). Direct observation of neighborhood stressors and environmental justice in the South Bronx, New York City. Population and Environment, 35(4), 477-496. https://doi.org/10.1007/s11111-013-0197-5

Morello-Frosch et al., R. (2007). Understanding the Cumulative Impacts of Inequalities in Environmental Health: Implications for Policy. Health Affairs, 30:5(December). 
Pong, R. W., DesMeules, M., \& Lagacé, C. (2009). Rural-urban disparities in health: How does Canada fare and how does Canada compare with Australia? Australian Journal of Rural Health, 17(1), 58-64. https://doi.org/10.1111/j.1440-1584.2008.01039.x

Richardson, E. A., Pearce, J., Mitchell, R., \& Kingham, S. (2013). Role of physical activity in the relationship between urban green space and health. Public health, 127(4), 318-324.

Sexton, K. (2012). Cumulative risk assessment: An overview of methodological approaches for evaluating combined health effects from exposure to multiple environmental stressors. International Journal of Environmental Research and Public Health, 9(2), 370-390. https://doi.org/10.3390/ijerph9020370

Stansfeld, S. A. (2015). Noise effects on health in the context of air pollution exposure. International Journal of Environmental Research and Public Health, 12(10), 12735-12760. https://doi.org/10.3390/ijerph121012735

Williams, R. B., Marchuk, D. a, Siegler, I. C., Barefoot, J. C., Helms, M. J., Brummett, B. H., ... Schanberg, S. M. (2008). Childhood socioeconomic status and serotonin transporter gene polymorphism enhance cardiovascular reactivity to mental stress. Psychosomatic Medicine, 70(1), 32-39. https://doi.org/10.1097/PSY.0b013e31815f66c3

\section{APPENDIX B: Canadian Community Health Survey (CCHS) - 2012 Data Dictionary}

1. Variable Name CCC_071

Question Name CCC_Q071

Concept Has high blood pressure

Question Remember, we're interested in conditions diagnosed by a health professional and are expected to last or have already lasted 6 months or more. ${ }^{\wedge}$ DOVERB_C ${ }^{\wedge}$ YOU2 have high blood pressure?

Universe All respondents

New Variable Name Has Hypertension

2. Variable Name DHHGAGE

Question Name

Concept Age - (G)

Question What is your age?

Universe All respondents

New Variable Name Age

3. Variable Name DHH_SEX

Question Name SEX_Q01

Concept Sex

Question Interviewer: Enter the respondent's sex. If necessary, ask: Is respondent male or female?

Universe All respondents

New Variable Name Sex

4. Variable Name INCGHH

Question Name

Concept Total household income from all sources - (D, G) 


\section{Content}

NO INCOME OR LESS THAN \$20,000

$\$ 20,000$ TO $\$ 39,999$

$\$ 40,000$ TO $\$ 59,999$

$\$ 60,000$ TO $\$ 79,999$

$\$ 80,000$ OR MORE

NOT STATED

Universe DHH_AGE $>15$ or PMKProxy $=1$

Note Beginning in 2010, the "Not Stated" category includes respondents for whom a person most knowledgeable about the household could not be identified (PMKProxy $=2$ ). Based on INCDHH. See documentation on derived variables

New Variable Name Income

\section{Variable Name EDUDR04}

Question Name

Concept Highest level of education - respondent, 4 levels - (D)

\section{Content}

LESS THAN SECONDARY SCHOOL GRADUATION

SEC. SCHOOL. GRA,,, NO POST-SEC.

SOME POST-SECONDARY EDUCATION

POST-SEC CERT./DIP OR UNIV. DEG

Universe (DHHDHSZ $=1$ and DHH_AGE $>=14$ ) or DHH_AGE $>15$ or PMKPROXY $=1$ Note Based on EDU_1, EDU_2, EDU_3, EDU_4A. See documentation on derived variables.

Beginning in 2010, the "Not Stated" category includes respondents for whom a person most knowledgeable about the household could not be identified (PMKProxy $=2$ ).

New Variable Name

6. Variable Name SMK_204

Question Name SMK_Q204

Concept Number of cigarettes smoked per day (daily smoker)

Question How many cigarettes ${ }^{\wedge}$ DOVERB ${ }^{\wedge}$ YOU1 smoke each day now?

Universe Respondents who answered SMK_202 $=(1,7$ or 8$)$ or SMK_01A = 8 and SMK_01B = 8

New Variable Name Smoked Cigarettes Daily

\section{Variable Name FVCGTOT}

Question Name

Concept Daily consumption - total fruits and vegetables - (D, G)

Content

LESS THAN 5 TIMES / SERVINGS PER DAY

5 TO 10 TIMES / SERVINGS PER DAY

MORE THAN 10 TIMES / SERVINGS PER DAY

NOT STATED

Universe All respondents

Note Based on FVCDTOT. The CCHS measures the number of times (frequency), not the amount consumed. See documentation on derived variables.

New Variable Name Daily Consumption of fruits/vegetables

8. Variable Name PACDEE

Based on PAC_1V, PAC_2A, PAC_2B, PAC_2C, PAC_2D, PAC_2E, PAC_2F, PAC_2G, PAC_2H, PAC_2I, PAC_2J, PAC_2K, PAC_2L, PAC_2M, PAC_2N, PAC_2O, PAC_2P, 
PAC_2Q, PAC_2R, PAC_2S, PAC_2T, PAC_2U, PAC_2W, PAC_2X, PAC_2Z, PAC_3A, PAC_3B, PAC_3C, PAC_3D, PAC_3E, PAC_3F, PAC_3G, PAC_3H, PAC_3I, PAC_3J, PAC_3K, PAC_3L, PAC_3M, PAC_3N, PAC_3O, PAC_3P, PAC_3Q, PAC_3R, PAC_3S, PAC_3T, PAC_3U, PAC_3W, PAC_3X, PAC_3Z

Description This variable is a measure of the average daily energy expended during leisure time activities by the respondent in the past three months.

Note Energy Expenditure (EE) is calculated using the frequency and duration per session of the physical activity as well as the MET value of the activity. The MET is a value of metabolic energy cost expressed as a multiple of the resting metabolic rate. For example, an activity of 4 METS requires four times the amount of energy as compared to when the body is at rest.

$\mathrm{EE}($ Energy Expenditure for each activity $)=(\mathrm{N} X \mathrm{D}$ X METvalue $) / 365$ Where: $\mathrm{N}=$ the number of times a respondent engaged in an activity over a 12 month period $\mathrm{D}=$ the average duration in hours of the activity MET value $=$ the energy cost of the activity expressed as kilocalories expended per kilogram of body weight per hour of activity (kcal/kg per hour)/365 (to convert yearly data into daily data)

MET values tend to be expressed in three intensity levels (i.e. low, medium, high). The CCHS questions did not ask the respondent to specify the intensity level of their activities. Therefore the MET values adopted correspond to the low intensity value of each activity. This approach is adopted from the Canadian Fitness and Lifestyle Research Institute because individuals tend to overestimate the intensity, frequency and duration of their activities.

Variable Name Activity MET Value

(kcal/kg/hr)

PACDEEA

PACDEEB

WALKING FOR EXERCISE

3

PACDEEC GARDENING OR YARD WORK

3

PACDEED

SWIMMING

BICYCLING

PACDEEE

POPULAR OR SOCIAL DANCE

PACDEEF

PACDEEG

HOME EXERCISES

3

PACDEEH

ICE HOCKEY

PACDEEI

PACDEEJ

PACDEEK

PACDEEL

PACDEEM

PACDEEN

PACDEEO

PACDEEP

ICE SKATING

4

PACDEEQ

PACDEER

PACDEES

PACDEET

PACDEEZ

IN-LINE SKATING OR ROLLERBLADING

JOGGING OR RUNNING*

GOLFING

EXERCISE CLASS OR AEROBICS

DOWNHILL SKIING OR SNOWBOARDING

BOWLING

BASEBALL OR SOFTBALL

TENNIS

WEIGHT-TRAINING

FISHING

VOLLEYBALL

PACDEEU

PACDEEW

BASKETBALL

SOCCER

OTHER (U)*

OTHER (W)*

PACDEEX

OTHER (X)*

4

4

4

2

3

4

3

3

5

6

5

4

4

4

* Jogging (MET value 7) and running (MET value 12) fall under one category. Therefore, the MET value for the combined activity is the average of their MET values (9.5). Since it is difficult to assign a MET value to the category "Other Activities", the MET value used is the average of the listed activities except for the average value of jogging and running. Here, the average value of jogging and running is replaced by the value for jogging only. Some activities have MET values 
lower than the average, however, this approach is consistent with other studies, such as the Campbell's Survey and the Ontario Health Survey (OHS).

* Times were assigned an average duration value for the calculation, as with NPHS: (13 minutes or .2167 hour, 23 minutes or .3833 hour, 45 minutes or .75 hour, 60 minutes or 1 hour

New Variable Name Physical Activity Index

9. Variable Name GEN_07

Question Name GEN_Q07

Concept Perceived life stress

Question Thinking about the amount of stress in your life, would you say that most days are...?

Universe Respondents aged 15 and over

Content

NOT AT ALL STRESSFUL

NOT VERY STRESSFUL

A BIT STRESSFUL

QUITE A BIT STRESSFUL

EXTREMELY STRESSFUL

DON'T KNOW

REFUSAL

New Variable Name Life Stress

10. Variable Name GEN_01

Question Name GEN_Q01

Concept Self-perceived health

Question In general, how would you say your health is now? Is it...?

Universe All respondents

Content

EXCELLENT

VERY GOOD

GOOD

FAIR

POOR

DON'T KNOW

REFUSAL

New Variable Name Perceived Health 


\section{References}

Adler, N. E., Epel, E. S., Castellazzo, G., \& Ickovics, J. R. (2000). Relationship of subjective and objective social status with psychological and physiological functioning: Preliminary data in healthy, white women. Health Psychology, 19(6), 586-592.

Agyemang, C., van Hooijdonk, C., Wendel-Vos, W., Ujcic-Voortman, J. K., Lindeman, E., Stronks, K., \& Droomers, M. (2007). Ethnic differences in the effect of environmental stressors on blood pressure and hypertension in the Netherlands. BMC Public Health, $7(1): 118$.

Akansel, N., \& Kaymakci, S. (2008). Effects of intensive care unit noise on patients: A study on coronary artery bypass graft surgery patients. Journal of Clinical Nursing, 17(21), 15811590.

Allen, R. W., Adar, S. D. Are both air pollution and noise driving adverse cardiovascular health effects from motor vehicles? Environmental Research, 111(1), 184-185.

Ames, S. C., Jones, G. N., Howe, J. T., Brantley, P. J. (2001. A prospective study of the impact of stress on quality of life: An investigation of low-income individuals with Hypertension. Annals of Behavioral Medicine, 23(2), 112-119.

Andrews, G. J. (2002). Towards a more place-sensitive nursing research: An invitation to medical and health geography. Nursing Inquiry 9(4), 221-238.

August, P. (2013). Hypertension in women. Advances in Chronic Kidney Disease, 20(5), 396401.

Babisch, W. (2008). Road traffic noise and cardiovascular risk. Noise \& Health. 10(38), 27-33.

Babisch, W. (2011). Cardiovascular effects of noise. Noise \& Health, 13(52), 201-204.

Babisch, W., Wolf, K., Petz, M., Heinrich, J., Cyrys, J., \& Peters, A. (2014). Associations between traffic noise particulate air pollution, hypertension, and isolated systolic hypertension in adults: The KORA study. Environmental Health Perspectives, 122(5), 492-498.

Babisch, W. (2014). Updated exposure-response relationship between road traffic noise and coronary heart diseases: a meta-analysis. Noise \& Health, 16(68), 1-9.

Barton, J., Hine, R., \& Pretty, J. (2009). The health benefits of walking in greenspaces of high natural and heritage value. Journal of Integrative Environmental Sciences, 6(4), 261-278.

Barton, J., \& Pretty, J. (2010). What is the best dose of nature and green exercise for improving mental health? A multi-study analysis. Environmental Science \& Technology, 44(10), 3947-3955. 
Baum, F. (1998). The new public health: An Australian perspective, Melbourne: Oxford University Press.

Baxter, J., \& Eyles, J. (1999). The utility of in-depth interviews for studying the meaning of environmental risk. The Professional Geographer, 51(2), 307-320.

Berman, M. G., Jonides, J., \& Kaplan, S. (2008). The cognitive benefits of interacting with nature. Psychological Science, 19(12), 1207-1212.

Black, D., O’Loughlin, K., Kendig, H., \& Wilson, L. (2012). Cities, envioronmental stressors, ageing and chronic disease. Australasian Journal on Ageing. 31(3), 147-151. doi:10.1111/j.1741-6612.2011.00552.x.

Blomkvist, V., Eriksen, C. A., Theorell, T., \& Rasmanis, G. (2005). Acoustics and psychosocial environment in intensive coronary care. Occupational and Environmental Medicine, 62(3), 1-8.

Brasner, M., Babisch, W., Davis, A., Brink, M., Clark, C., Janssen, S., \& Stansfeld, S. (2014). Auditory and non-auditory effects of noise on health. The Lancet, 383(9925), 1325-1332.

Brauer, M., Hoek, G., Van Vliet, P., Meliefste, K., Fischer, P. H., Wijga, A., Koopman, L. P., Neijens, H. J., Gerritsen, J., Kerkhof, M., Heinrich, J., Bellander, T., \& Brunekreef, B. (2002). Air pollution from traffic and the development of respiratory infections and asthmatic and allergic symptoms in children. American Journal of Respiratory and Critical Care Medicine, 166(8), 1092-1098. doi:10.1164/rccm.200108-007OC.

Brook, R. D., Franklin, B., Cascio, W., Hong, Y., Howard, G., Lipsett, M., Luepker, R., Mittleman, M., Samet, J., Smith Jr., S. C., Tager, I. (2004). Air pollution and cardiovascular disease: A statement for healthcare professionals from the expert panel on population and prevention science of the American Heart Association. Circulation, 109(21): 2655-2671.

Brook, R. D., Rajagopalan, S., Pope, C. A., Brook, J. R., Bhatnagar, A., Diez-Roux, A. V., Holguin, F., Hong, Y., Luepker, R. V., Mittleman. M. A., Peters, A., Siscovick, D., Smith, S. C., Whitesel, L., \& Kaufman, J. D. (2010). Particulate matter air pollution and cardiovascular disease: An update to the scientific statement from the American heart association. Circulation, 121(21), 2331-2378.

Brook, R. D., \& Kousha, T. (2015). Air pollution and emergency department visits for hypertension in Edmonton, and Calgary, Canada: A case-crossover study. American Journal for Hypertension, 28(9), 1121-1126.

Buzzelli, M., \& Jerrett, M. (2004). Racial gradients of ambient air pollution exposure in Hamilton, Canada. Environment and Planning A, 36(10), 1855-1876.

Buzzelli, M. (2007). Bourdieu does environmental justice? Probing the linkages between population health and air pollution epidemiology. Health \& Place, 13, 3-13. 
Carpenter, L. L., Carvalho, J. P., Tyrka, A. R., Wier, L. M., Mello, A. F., Mello, M. F., Anderson, G. M., Wilkinson, C. W., Price, W. H. (2007). Decreased adrenocorticotrophic hormone and cortisol responses to stress in healthy adults reporting significant childhood maltreatment. Biological Psychiatry, 62(10), 1080-1087.

Clougherty, J. \& Kubzansky, L. D. (2009). A framework for examining social stress and susceptibility to air pollution in respiratory health. Environmental Health Perspectives, 117(9), 1351-1358.

City of Toronto. (2016). Neighbourhood profiles. Retrieved June 18, 2018, from https://www.toronto.ca/city-government/data-research-maps/neighbourhoodscommunities/neighbourhood-profiles/.

Davies, H. W., Vlaanderen, J., Henderson, S. B., \& Brauer, M. (2018). Correlation between co-exposures to noise and air pollution from traffic sources. Occupational and Environmental Medicine, 66(5), 347-350.

Day, R. (2007). Place and the experience of air quality. Health \& Place, 13(1), 249-260.

Dean, J., van Dooren, K., \& Weinstein, P. (2011). Does biodiversity improve mental health in urban settings? Medical Hypotheses, 76(6), 877-880.

Dear, M., \& Wolch, J. (1989). The power of geography: How territory shapes social life (Boston: Unwin Hyman).

Dunn, J. R., \& Hayes, M. (2000). Social inequality, population health, and housing: A study of two Vancouver neighbourhoods. Social Science and Medicine, 51(4), 563-587.

Dzhambov, A. M., Markevych, I., Tilov, B., Arabadziev, Z., Stoyanov, D., Gatseva, P., \& Dimitrova, D. D. (2018). Pathways linking residential noise and air pollution to mental ill-health in young adults. Environmental Research, 166, 458-465.

Environment Canada. (2008). National air pollution surveillance (NAPS) network. Environment Canada. Retrieved from http://publications.gc.ca/collections/collection_2008/ec/En49-27-39.pdf.

Epp, J. (1986). Achieving health for all: a framework for health promotion. Ottawa, ON: Health and Welfare Canada. Retrieved from Health Canada website: https://www.canada.ca/en/health-canada/services/health-care-system/reportspublications/health-care-system/achieving-health-framework-health-promotion.html.

European Commission. (2016). Health variables in SILC- Methodology. European Commission. Retrieved from ec.europa.eu/eurostat/statisticsexplained/index.php/Health_variables_in_SILC_-_methodology.

European Parliament, \& Council of the European Union (2002). Directive 2002/49/EC- Relating to the assessment and management of environmental noise. Official Journal of the 
European Communities. Retrieved from https://eur-lex.europa.eu/legalcontent/EN/TXT/HTML/?uri=CELEX:52011DC0321\&from=EN

Euteneuer, F., Mills, P. J., Pung, M. A., Rief, W., \& Dimsdale, J. E. (2014). American Psychological Association. 33(11), 1366-1372. doi:10.1037/hea0000004.

Evans, G. W., \& Cohen, S. (1982). Environmental Stress. New York: Cambridge University Press.

Eyles, J. (1993). From disease ecology and spatial analysis to...? The challenges of medical geography in Canada. Health and Canadian Society, 1(1), 113-146.

Eyles, J. (1997). Environmental health research: Setting an agenda by spinning our wheels or climbing the mountain? Health \& Place, 3(1), 1-13.

Evergreen. (2004). Green space acquisition and stewardship in Canada's urban municipalities. Evergreen, 1-42.

Foster, H. D. (1987). Diseases and cancers of the thyroid, nervous system and skin. Medical Hypotheses, 24, 249-263.

Forester, M., Basagaña, X., Aguilera, I., Rivera, M., Agis, D., Bouso, L., Deltell, A., Marrugat, J., Ramos, R., Sunyer, R., Vila, J., Elosua, R., \& Künzli, N. (2014). Association of longterm exposure to traffic-related air pollution with blood pressure and hypertension in an adult population-based cohort in Spain (the REGICOR study). Environmental Health Perspectives, 122(4), 404-411.

Franklin, B, A., Brook, R., Pope, A. (2015). Air pollution and cardiovascular disease. Current Problems in Cardiology, 40(5), 207-238.

Fuks, K., Moebus, S., Hertel, S., Viehmann, A., Nonnemacher, M., \& Dragano, N. (2011). Longterm urban particulate arterial blood pressure air pollution, traffic noise, and arterial blood pressure. Environmental Health Perspectives, 119(12): 1706.

Fuks, K. B., Weinmayr, G., Basagaña, X., Gruzieva, O., Hampel, R., Oftedal, B, Sørensen, M., Wolf, K., Aamodt, G., Marit Aasvang, G., Aguilera, I., Becker, T., Beelen, R., Brunekreef, B., Caracciolo, B., Cyrys, J., Elosua, R., Thorup Eriksen, K., Forester, M., Fratiglioni, L., Hilding, A., Houthuijs, D., Korek, M., Künzli, N., Marrugat, J., Nieuwenhuijsen, M., Östenson, C., Penell, J., Pershagen, G., Raaschou-Nielsen, O., S, W. J.R., Peters, A., \& Hoffmann, B. (2017). Long-term exposure to ambient air pollution and traffic noise and incident hypertension in seven cohorts of the European study of cohorts for air pollution effects (ESCAPE). European Heart Journal, 38(29), 983-990.

Gatrell, A. C., \& Elliott, S. J. (2009). Geographies of health: An introduction. Chichester, United Kingdom: Wiley-Blackwell. 
Gildlöf-Gunnarsson, A., \& Öhrström, E. (2007). Noise and well-being in urban residential environments: The potential role of perceived availability to nearby green areas. Landscape and Urban Planning, 83, 115-126.

Gildlöf-Gunnarsson, A., Öhrström, E., \& Forssén, J. (2012). The effect of creating a quiet side on annoyance and sleep disturbances due to road traffic noise. $41^{\text {st }}$ International Congress and Exposition on Noise Control Engineering 2012, INTER-NOISE. Retrieved from: http://publications.lib.chalmers.se/records/fulltext/159571/local_159571.pdf

Gladwell, V. F., Brown, D. K., Barton, J. L., Tarvainen, M. P., Kuoppa, P., Pretty, J., Suddaby, J. M., \& Sandercock, G. R. H. (2012). The effects of views of nature on autonomic control. European Journal of Applied Physiology, 112(9), 3379-3386.

Groenewegen, P. P., van den Berg, A. E., de Vries, S., \& Verheij, R. A. (2006). Vitamin G: effects of greenspace on health, well-being, and social safety. BMC Public Health, 6(1): 149.

Hamer, M., \& Steptoe, A. (2012). Cortisol Responses to mental stress and incident hypertension in healthy men and women. The Journal of Clinical Endocrinology \& Metabolism, 97(1), E29-E34.

Hammer, M. S., Swinburn, T. K., Nietzel, R. L. (2014). Environmental noise pollution in the United States: Developing an effective public health response. Environmental Health Perspectives, 122(2), 115-119.

Hansen, M. M., Jones, R., \& Tocchini, K. (2017). Shinrin-Yoku (Forest bathing) and nature therapy: A state-of-the-art review. International Journal of Environmental Research and Public Health, 14(8): 851.

Hansmann, R., Hug, S. M., \& Seeland, K. (2007). Restoration and stress relief through physical activities in forests and parks. Urban Forestry \& Urban Greening, 6(4), 213-225.

Hayes, M. V. (1999). Man, disease and environmental associations: From medical geography to health inequalities. Progress in Human Geography, 23(2), 289-296.

Hayes, M. V., \& Dunn, J. R. (1998). 1998 Population Health in Canada: A systematic review (Ottawa: Canadian Policy Research Networks).

Hazelhurst, M. F., Nurius, P. S., Hajat, A. (2018). Individual and neighbourhood stressors, air pollution and cardiovascular disease. International Journal of Environmental Research and Public Health, 15(3): 472.

Health Canada. (1994). Strategies for Population Health: Investing in the Health of Canadians. Health Canada. Retrieved from http://www.hc-sc.gc.ca/hppb/phdd/pdf/e_strateg.pdf 
Health Canada. (1998). Taking Action on Population Health. Ottawa, ON: Health Canada. Retrieved from http://publications.gc.ca/collections/Collection/H88-3-302001/pdfs/other/taph_e.pdf.

Hollingworth, S. A., Kim, D. D., \& Jagals, P. (2016). A review of medication use as an indicator of human health impact in environmentally stressed areas. Annals of Global Health, 82(1), 111-118. doi:11.1016/j.aogh.2016.01.010.

Hsu, S. M., Ko, W, J., Liao, W. C., H, S. J., Chen, R, J., Li, C, Y., Hwang, S. L. (2010). Associations of exposure to noise with physiological and psychological outcomes among post-cardiac surgery patients in ICUs. Clinics, 65(10), 985-989.

Hystad, P., Setton, E., Cervantes, A., Poplawski, K., Deschenes, S., Brauer, M., Donkelaar, A. van., Lamsal, L., Martin, R., Jerrett, M., \& Demers, P. (2011). Creating national air pollution models for population exposure assessment in Canada. Environmental Health Perspectives, 119(8), 1123-1129.

Jenerette, G. D., Harlan, S. L., \& Stefanov, W. L. (2011). Ecosystem services and urban heat riskscape moderation: water, green spaces, and social inequality in Phoenix, USA. Ecological Society of America, 21(7), 2637-2651.

Jerrett, M., Burnett, R. T., Kanaroglou, P., Eyles, J., Finkelstein, N., Giovis, G., \& Brook, J. R. (2001). A GIS- Environmental justice analysis of particulate air pollution in Hamilton, Canada. Environment and Planning A, 33(6), 955-973.

Jerrett, M., Burnett, R. T., Goldberg, M., Sears, M., Krewski, D., Catalan, R., Kanaroglou, P., Giovis, C., \& Finkelstein, N. (2003). Spatial analysis for environmental health research: Concepts, methods, and examples. Journal of Toxicology and Environmental Health, Part A 66(16), 1783-1810.

Kearns, R. A., \& Gesler, W. M. (1998). Putting Health into Place: Landscape, Identity, and Well-being. New York: Syracuse University Press.

Kearns, R.A. and Moon, G. (2002). From medical to health geography: theory, novelty, and place in a decade of change. Progress in Human Geography, 26, 587-607.

Keniger, L. E., Gaston, K. J., Irvine, K. N., \& Fuller, R. A. (2013). What are the benefits of interacting with nature? International Journal of Environmental Research and Public Health, 10(3), 913-935.

Kluizenaar, Y. de (2015). Adverse effects of long term exposure to road traffic noise. (Doctoral dissertation). Retrieved from the Erasmus University Rotterdam TU Delft Library Digital Repository. 527198.

Kluizenaar, Y. de., van Lenthe, F. J., Visschedijk, A. J. H., Zandveld, P. Y. J., Miedema, H. M. E., \& Machekbach, J. P. (2013). Road traffic noise, air pollution components and cardiovascular events. Noise \& Health, 15(67), 388-397. 
Koolhaas, J. M., Bartolomucci, A., Buwalda, B., de Boer, S. F., Flügge, G., Korte, S. M., Meerlo, P., Murison, R., Olivier, B., Palanza, P., Richter-Levin, G., Sgoifo, A., Steimer, T., Stiedl, O., van Dijk, G., Wöhr, M., \& Fuchs, E. (2011). Stress revisited: A critical evaluation of the stress concept. Neuroscience and Biobehavioral Reviews 35(5), 12911301.

Lachowycz, K., \& Jones, A. P. (2014). Does walking explain associations between access to greenspace and lower mortality? Social Science \& Medicine, 107, 9-17.

Lalonde, M. (1974). A new perspective on the health of Canadians. Ottawa, ON: Minister of Supply and Services Canada. Retrieved from Public Health Agency of Canada website: http://www.phac-aspc.gc.ca/ph-sp/pdf/perspect-eng.pdf.

Leonardi, F. (2018). The Definition of Health: Towards New Perspectives. International Journal of Health Services, $0(0), 1-14$.

Lima, R., Wofford, M., \& Reckelhoff, J. F. (2012). Hypertension in postmenopausal women. Current Hypertension Reports, 14(3), 254-260.

Luginaah, I.L. (2009). Health geography in Canada: where are we headed? The Canadian Geographer, 53, 91-9.

Macintyre, S., Ellaway, A., \& Cummins, S. (2002). Place effects on health: How can we conceptualise, operationalise, and measure them? Social Science \& Medicine, 55(1), 125139.

Martin, C., \& McQueen, D. (Eds.). (1989). Readings for a New Public Health. Edinburgh: Edinburgh University Press.

McKinlay, J. B. (1993). The promotion of health through planned sociopolitical change; challenges for research and policy. Social Science and Medicine, 36(2), 109-117.

Mechanic, D. (1993). Social research in health and the American sociopolitical context: the changing fortunes of medical sociology. Social Science and Medicine, 36(2), 95-102.

Mery, G., Majumder, S., Brown, A., \& Dobrow, M. J. (2017). What do we mean when we talk about the Triple Aim? A systematic review of evolving definitions and adaptations of the framework at the health system level. Health Policy, 121, 629-636.

Mitchell \& Popham. (2008). Effect of exposure to natural environment on health inequalities: an observational population study. The Lancet, 372(9650), 1655-1660.

Moeller, D. W. (2005). Environmental Health. Cambridge, Mass: Harvard University Press.

Moloughney, B. P. (2004). Housing and population health: The state of current research knowledge. Ottawa, ON: Canadian Institute for Health Information. 
Mobley, L. R., Root, E. D., Finkelstein, E. A., Khavjou, O., Farris, R. P., Will, J. C. (2006). Environment, obesity, and Cardiovascular disease risk in low-income women. American Journal of Preventative Medicine, 30(4), 327-332.

Münzel, T., Gori, T., Babisch, W., \& Basner, M. (2014). Cardiovascular effects of environmental noise exposure. European Heart Journal, 35(13), 829-836.

Münzel, T., Schmidt, F. P., Steven, S., Herzog, J., Daiber, A., \& Sørensen, M. (2018). Environmental noise and the cardiovascular system. Journal of the American College of Cardiology, 71(6): 688 .

Natural England. (2010). Nature nearby: Accessible natural greenspace guidance. Sheffield: Natural England.

Newby, D. E., Mannucci, P. M., Tell, G. S., Baccarelli, A. A., Brook, R. D., Donaldson, K., Forastiere, F., Franchini, M., Franco, O. H., Graham, I., Hoek, G., Hoffmann, B., Hoylaerts, M. F., Künzli, N., Mills, N., Pekkanen, J., Peters, A., Piepoli, M. F., Rajagopalan, S., Storey, R. F. (2015). Expert position paper on air pollution and cardiovascular disease. European Heart Journal, 36(2), 83-93.

Newbold, B., \& Danforth, J. (2003). Health status and Canada's immigrant population. Social Science \& Medicine, 57(10), 1981-1995.

Oiamo, T. H. (2014). Environmental health effects of multiple exposures: systemic risks and the Detroit river international crossing study. (Doctoral dissertation). Retrieved from the University of Western Ontario Electronic Thesis and Dissertation Repository. 2553.

Oiamo, T. H., Davies, H. W., Rainham, D., \& Rinner, C. (2017). Environmental noise study in the city of Toronto

Oiamo, T. H., Johnson, M., Tang, K., \& Luginaah, I. N. (2015). Assessing traffic and industrial contributions to ambient nitrogen dioxide and volatile organic compounds in a low pollution urban environment. The Science of the Total Environment, 529, 149-157.

Persson, P. B., \& Zakrisson, A. (2016). Stress. Acta Physiologica 216(2), 149-152.

Peters, E. (1996). 'Urban' and 'Aboriginal': An impossible contradiction? Visions of the Heart: Canadian Aboriginal Issues, eds. D. Long and O.P. Dickason (Toronto: Harcourt Brace \& Company), 305-334.

Pimenta, E. (2012). Hypertension in women. Hypertension Research: Official Journal of the Japanese Society of Hypertension, 35(2): 148.

Poulter, N. R., Prabhakaran, D., \& Caulfield, M. (2015). Hypertension. Lancet, 386(9995), 801812. 
Robinson, W. (1950). Ecological correlations and the behaviour of individuals. Americal Sociological Review, 15, 351-357.

Robitaille, C., Dai, S., Waters, C., Loukine, L., \& Bancej, C. (2012). Diagnosed hypertension in Canada: incidence, prevalence and associated mortality. Canadian Medical Association, 184(1):E49.

Rosenfield, S. (2012). Triple jeopardy? Mental health at the intersection of gender, race, can class. Social Science \& Medicine, 74(11), 1791-1801.

Scallan, C., Doonan, R. J., Daskalopoulou, S. S. (2010). The combined effect of hypertension and smoking on arterial stiffness. Clinical and Experimental Hypertension, 32(6), 319328.

Schneiderman, N., Ironson, G., \& Siegel, S. D. (2005). Stress and health: Psychological, behavioural, and biological determinants. Annual Review of Clinical Psychology, 1(1), 607-628.

Sexton, K. (2012). Cumulative risk assessment: An overview of methodological approaches for 1 evaluating combined health effects from exposure to multiple environmental stressors. International Journal of Environmental Health and Public Health, 9(2), 370-390.

Spenser, R. L., \& Deak, T. (2017). A users guide to the HPA axis research. Physiology \& Behaviour, 178, 43-65.

Spreng, M. (2000). Possible health effects of noise induced cortisol increase. Noise \& Health, 2(7), 59-64.

Stansfeld, S. A. (2015). Noise effects on health in the context of air pollution exposure. International Journal of Environmental Research and Public Health, 12(10), 1273512760.

Statistics Canada. (2011). Canadian Community Health Survey (CCHS) - Annual ComponentDerived Variable (DV) Specifications. Statistics Canada. Retrieved from http://sda.chass.utoronto.ca/sdaweb/dli2/cchs/cchs2011/more_doc/CCHS_20112012_Derived_Variables.pdf

Statistics Canada. (2016). Canadian Community Health Survey - Annual Component (CCHS). Statistics Canada. Retrieved from http://www23.statcan.gc.ca/imdb/p2SV.pl?Function=getSurvey\&SDDS=3226.

Subramanian, S. V., Huijts, T., \& Avendano, M. (2010). Self-reported health assessments in 2002 World Health Survey: How do they correlate with education? Bulletin of the World Health Organization 88(2), 131-138.

Taylor, L., \& Hochuli, D. F. (2015). Creating better cities: How biodiversity and ecosystem functioning enhance urban residents' wellbeing. Urban Ecosystems, 18(3), 747-762. 
Tétreault, L. F., Perron, S., \& Smargiassi, A. (2013). Cardiovascular health, traffic-related air pollution and noise: are associations mutually confounded? A systematic review. International Journal of Public Health, 58(5), 649-666.

Thorpe, A., \& Harrison, R. M. (2008). Sources and properties of non-exhaust particulate matter from road traffic: A review. Science of the total environment, 200, 270-282. doi:10.1016/j.scitotenv.2008.06.007

Toronto Public Health. (2015). The Unequal City 2015: Income and Health Inequalities in Toronto. Retrieved from https://www.toronto.ca/legdocs/mmis/2015/hl/bgrd/backgroundfile-79096.pdf.

Tyrväinen, L., Ojala, A., Korpela, K., Lanki, T., Tsunetsugu, Y., \& Kagawa, T. (2014). The influence of urban green environments on stress relief measures: A field experiment. Journal of Enviornmental Psychology, 38, 1-9.

Wakefield, S., Yeudall, F., Taron, C., Reynolds, J., \& Skinner, A. (2007). Growing urban health: Community gardening in South-East Toronto. Health Promotion International, 22(2), 92101.

World Health Organization. (1999). Guidelines for community noise. WHO, Geneva.

World Health Organization. (2013). A global brief on hypertension. World Health Organization, $1-40$.

World Health Organization. (2016a). Environmental Health. WHO: Regional Office for SouthEast Asia. Retrieved from http://www.searo.who.int/topics/environmental_health/en/.

World Health Organization. (2016b). Urban green spaces and health. Copenhagen: WHO Regional Office for Europe, 1-92.

Yil-Pelkonen, V., Scott, A. A., Vippola, V., \& Setälä, H. (2017). Trees in urban parks and forests reduce $\mathrm{O}_{3}$, but not $\mathrm{NO}_{2}$ concentrations in Baltimore, MD, USA. Atmospheric Environment, 167, 73-80. 